\title{
PI3K p110 inactivation antagonizes chronic lymphocytic leukemia and reverses T cell immune suppression
}

\author{
Shuai Dong, ${ }^{1,2}$ Bonnie K. Harrington, ${ }^{2,3}$ Eileen Y. Hu, ${ }^{2,4}$ Joseph T. Greene, ${ }^{2,5}$ Amy M. Lehman, ${ }^{6}$ Minh Tran, ${ }^{2}$ Ronni L. Wasmuth, ${ }^{2}$ \\ Meixiao Long, ${ }^{2}$ Natarajan Muthusamy, ${ }^{2}$ Jennifer R. Brown, ${ }^{7}$ Amy J. Johnson, ${ }^{2,8}$ and John C. Byrd ${ }^{1,2}$ \\ 'Division of Pharmaceutics and Pharmaceutical Chemistry, College of Pharmacy, ${ }^{2}$ Division of Hematology, Department of Internal Medicine and Comprehensive Cancer Center, ${ }^{3}$ College of Veterinary Medicine, \\ ${ }^{4}$ Medical Scientist Training Program, ${ }^{5}$ Molecular, Cellular, and Developmental Biology Program, and ${ }^{6}$ Center for Biostatistics, The Ohio State University, Columbus, Ohio, USA. ${ }^{7}$ Department of Medical \\ Oncology, Dana-Farber Cancer Institute, Boston, Massachusetts, USA. ${ }^{8}$ anssen Research and Development LLC, Spring House, Pennsylvania, USA.
}

\begin{abstract}
Targeted therapy with small molecules directed at essential survival pathways in leukemia represents a major advance, including the phosphatidylinositol-3'-kinase (PI3K) p110 $\delta$ inhibitor idelalisib. Here, we found that genetic inactivation of $\mathrm{p} 110 \delta\left(\mathrm{p} 110 \delta^{\mathrm{Dg10A} / \mathrm{D910A}}\right)$ in the E $\mu$-TCL1 murine chronic lymphocytic leukemia (CLL) model impaired B cell receptor signaling and B cell migration, and significantly delayed leukemia pathogenesis. Regardless of TCL1 expression, p110 $\delta$ inactivation led to rectal prolapse in mice resembling autoimmune colitis in patients receiving idelalisib. Moreover, we showed that $p 110 \delta$ inactivation in the microenvironment protected against CLL and acute myeloid leukemia. After receiving higher numbers of TCL1 leukemia cells, half of $\mathrm{p} 110 \delta^{\mathrm{D910A} / 0910 \mathrm{~A}}$ mice spontaneously recovered from high disease burden and resisted leukemia rechallenge. Despite disease resistance, $\mathrm{p} 110 \delta^{\mathrm{D910A} / 0910 \mathrm{~A}}$ mice exhibited compromised $\mathrm{CD} 4^{+}$and $\mathrm{CD} 8^{+} \mathrm{T}$ cell response, and depletion of $\mathrm{CD4}^{+}$or $\mathrm{CD8}{ }^{+} \mathrm{T}$ cells restored leukemia. Interestingly, $\mathrm{p} 110 \delta^{\mathrm{Dg} 10 \mathrm{~A} / \mathrm{D} 10 \mathrm{~A}}$ mice showed significantly impaired Treg expansion that associated with disease clearance. Reconstitution of $\mathrm{p} 110 \delta^{\mathrm{Dg} 10 \mathrm{~A} / \mathrm{Dg} 10 \mathrm{~A}}$ mice with $\mathrm{p} 110 \delta^{\mathrm{WT} / \mathrm{WT}}$ Tregs reversed leukemia resistance. Our findings suggest that $\mathrm{p} 110 \delta$ inhibitors may have direct antileukemic and indirect immuneactivating effects, further supporting that $\mathbf{p} 110 \delta$ blockade may have a broader immune-modulatory role in types of leukemia that are not sensitive to $110 \delta$ inhibition.
\end{abstract}

\section{Introduction}

The development of chronic lymphocytic leukemia (CLL) is the consequence of malignant cell transformation, microenvironmentinduced proliferation, and evasion of immune surveillance (1-3). Overwhelming evidence has highlighted the critical role that the leukemia microenvironment plays in the progression of CLL and other hematologic cancers. The leukemia microenvironment is composed of various cell types, including T cells, nurse-like cells, and stromal cells, the majority of which interact to collectively produce chemokines and cytokines to promote malignant cell tissue homing, retention, and proliferation (1). Another key aspect of the leukemia microenvironment is that CLL cells reshape the surrounding environment into a cancer-promoting and immunosuppressive milieu $(1,2)$. CLL cells can attract protective accessory cells by producing chemokines and cytokines (4-7). Furthermore, CLL cells evade immune destruction by expressing immunosuppressive molecules, secreting immunosuppressive cytokines and exosomes, increasing regulatory

Authorship note: AJJ and JCB contributed equally to this work. Conflict of interest: JRB receives research funding and consulting fees from Gilead Sciences and Sun Pharmaceutical, and consulting fees from Janssen and AbbVie. AJJ is an employee of Janssen Research and Development. License: Copyright 2019, American Society for Clinical Investigation. Submitted: January 23, 2018; Accepted: October 2, 2018. Reference information: / Clin Invest. 2019;129(1):122-136. https://doi.org/10.1172/JCI99386.
T cells (Tregs), and inducing myeloid-derived suppressor cells (MDSCs) (8-10).

The Bruton tyrosine kinase (BTK) inhibitor ibrutinib has been shown to have immunomodulatory functions through inhibiting direct tumor-mediated disease suppression, MDSC function, and regulatory B cell function (11-14). Through irreversibly inhibiting IL-2-inducible T cell kinase (ITK), ibrutinib can polarize CD4 ${ }^{+}$ $\mathrm{T}$ cells to the antitumor Th1 lineage and expand effector $\mathrm{T}$ cells (15). Presumably through both its BTK-inhibiting and its ITKinhibiting properties, ibrutinib enhances generation and function of chimeric antigen receptor (CAR) $\mathrm{T}$ cells and improves PD-1 blockade efficacy in several solid tumor models $(13,14)$. Acalabrutinib, despite lacking inhibitory activity against ITK, still can reverse CLL immune suppression by reducing CD200 and BTLA expression on CLL cells and PD- 1 and CTLA4 expression on CD8 ${ }^{+}$ $\mathrm{T}$ cells (13). The phosphatidylinositol-3'-kinase (PI3K) p110 inhibitor idelalisib also appears to affect the immune compartment, as evidenced by the treatment-induced autoimmune side effects such as pneumonitis and colitis observed in patients receiving idelalisib therapy $(16,17)$. However, the precise mechanism of idelalisib-induced immune activation remains elusive.

PI3K p1108, the catalytic isoform preferentially expressed in the hematopoietic system, contributes significantly to immune cell development and function (18-22). Activation of many membrane receptors of immune cells converges on the PI3K pathway $(23,24)$. In CLL cells, PI3K p110 $\delta$ is abundantly expressed and constitutively activated $(25,26)$. Inhibitors of PI3K p110 $\delta$ such as 
idelalisib or duvelisib have shown significant clinical activity in relapsed/refractory CLL $(27,28)$. While preclinical studies overwhelmingly focused on the effect of $\mathrm{p} 110 \delta$ blockade in the leukemia cells, little is known about the effect of p110 $\delta$ blockade in the neighboring cells of the microenvironment. p110 $\delta$ kinase activity is important for the functions of $\mathrm{T}$ cells, natural killer cells, monocytes, macrophages, and dendritic cells in the CLL microenvironment (29). This raises the question of whether part of idelalisib's therapeutic activity comes from inhibiting $\mathrm{p} 110 \delta$ in these important surrounding accessory cells.

Emerging evidence has shown an immune-activating effect with pharmacologic p110 $\delta$ inhibitors $(16,30-32)$. When given as initial therapy for CLL, idelalisib causes frequent hepatotoxicity associated with higher $\mathrm{CD}^{+} \mathrm{T}$ cell infiltration in the liver and lower numbers of Tregs in the blood (16). Murine and human $\mathrm{CD}^{+} \mathrm{T}$ cells treated with idelalisib in vitro exhibit an undifferentiated phenotype and persist longer after transfer into tumor-bearing mice, which leads to better antitumor immunity in both murine syngeneic and human xenograft tumor models (32). Coculture of CLL cells with $\mathrm{T}$ cells in the presence of idelalisib reduces CLL-induced T cell suppression (30). However, inhibitors have variable specificity, and the immune-activating effects of idelalisib could be confounded by the lowered disease burden. Therefore, the precise mechanism of $\mathrm{p} 110 \delta$ blockade in the complexity of the leukemia microenvironment is best addressed using genetic animal models.

Mice with genetically inactivated $\mathrm{p} 110 \delta\left(\mathrm{p} 110 \delta^{\mathrm{D} 910 \mathrm{~A} / \mathrm{D} 910 \mathrm{~A}}\right)$ have provided invaluable insight into the function of $\mathrm{p} 110 \delta . \mathrm{p} 110 \delta^{\mathrm{D} 910 \mathrm{~A} / \mathrm{D} 910 \mathrm{~A}}$ mice have $\mathrm{CD}^{+} \mathrm{T}$ cells that are compromised in response to phytohemagglutinin and concanavalin A stimulation, and show dampened OT-II OVA-specific responses and impaired Th1/Th2 differentiation $(33,34)$. Despite the compromised $T$ cell responses, $\mathrm{p} 110 \delta^{\mathrm{D} 910 \mathrm{~A} / \mathrm{D} 910 \mathrm{~A}}$ mice are protected against a broad range of subcutaneously engrafted solid tumors (31). This is partly due to the impairment of Treg expansion and function that reverses antitumor immune tolerance and facilitates $\mathrm{CD} 8^{+} \mathrm{T}$ cell-mediated cytotoxicity (31). This antitumor immunity of $\mathrm{p} 110 \delta^{\mathrm{D} 910 \mathrm{~A} / \mathrm{D} 910 \mathrm{~A}}$ mice can be recapitulated when solid tumor-implanted mice are treated with the p110 $\delta$ inhibitor IC87114 (31). Tregs are found to be expanded in many types of leukemia, including CLL and acute myeloid leukemia (AML), and are associated with disease progression and poor prognosis (35-37). Therefore, it is reasonable to hypothesize that impaired Treg expansion could be beneficial in both CLL and AML.

However, owing to the immune-cell origin and the disseminated nature of hematologic malignancies, the mechanism of immune tolerance may be distinct from that in solid tumors. As a result of the poor vasculature of bulky tumors, immune cells have limited access to tumor cells. Solid tumors exhibit localized immune tolerance, and systemic immune dysfunction is only associated with advanced cancer. In contrast, the development of hematologic malignancies involves blood, bone marrow, and secondary lymphoid organs, where leukemia cells are in constant interaction with the normal immune cells. Moreover, many hematologic malignancies, including CLL, carry little neoantigen compared with many solid tumors, which further facilitates its immune tolerance (38). Systemic immune dysfunction is a hallmark of CLL, highlighted by the hypogammaglobulinemia and susceptibility to infections. CLL patients also exhibit profound T cell dysfunction, highlighted by increased $\mathrm{T}$ cell numbers yet severely compromised functions including proliferation and cytokine production (9, 39-42). In addition, accessory immune cells can interact with leukemic B cells as they would with normal B cells during normal immune responses. For example, binding between CD40 ligand (CD4OL) on T cells and $\mathrm{CD} 40$ on B cells plays a critical role in generating humoral responses (43). However, this interaction can be exploited by CLL-B cells for leukemia survival and proliferation (44).

Notably, the E $\mu$-TCL1 (TCL1) mouse model, one of the most well-characterized CLL murine models (45-50), serves as an excellent tool for investigating immunomodulatory agents. Leukemia from E $\mu$-TCL1 mice represents unmutated IGHV CLL, the most aggressive form of CLL (45). Upon leukemia development, $\mathrm{E} \mu$-TCL1 mice exhibit T cell defects similar to what is observed in CLL patients $(46,47,49)$. These defects include aberrantly expressed genes for actin remodeling, impaired immunologic synapse formation, compromised $\mathrm{T}$ cell signaling, loss of $\mathrm{T}$ cell receptor diversity, clonal expansion of $\mathrm{T}$ cell populations, and an exhausted T cell phenotype $(46,47,49)$. These T cell defects found in E $\mu$-TCL1 mice can be reversed by lenalidomide, an immunomodulatory agent used in CLL patients $(42,51)$.

PI3K p110 inhibitors have shown broad activity in the treatment of hematologic malignancies. However, the role of $\mathrm{p} 110 \delta$ inhibition in the leukemia microenvironment has not yet been addressed in a spontaneous, disseminated leukemia model. We sought to examine this using the E $\mu$-TCL1 transgenic mouse model of CLL and a mouse model of $\mathrm{p} 110 \delta$ genetic inactivation $\left(\mathrm{p} 110 \delta^{\mathrm{D} 910 \mathrm{~A} / \mathrm{D} 910 \mathrm{~A}}\right)$ to fully interrogate the effect of global and selective $110 \delta$ inhibition in the nonleukemic compartment in a complete immune microenvironment. These findings were confirmed in a second murine model of AML, providing evidence of the potential of $\mathrm{p} 110 \delta$ inhibition in providing enhanced immune surveillance of leukemia.

\section{Results}

Global p110 k kinase inactivation significantly delays spontaneous leukemia development. The E $\mu$-TCL1 transgenic mouse represents a model of IGHV unmutated CLL with epigenetic patterns, immune suppression characteristics, and response to pharmacologic agents similar to the human disease $(45,46,49,50,52,53)$. To assess the influence of $\mathrm{p} 110 \delta$ loss of function on B cell receptor (BCR) signaling in this model, E $\mu$-TCL1 transgenic mice were crossed with $\mathrm{p} 110 \delta^{\mathrm{D} 910 \mathrm{~A} / \mathrm{D} 910 \mathrm{~A}}$ (homozygous kinase-dead mutation) mice (18). TCL1 functions as an AKT kinase coactivator through binding and enhancing AKT kinase activity $(52,54)$. Since $\mathrm{p} 110 \delta^{\mathrm{D} 910 \mathrm{~A} / \mathrm{D} 910 \mathrm{~A}}$ mice were reported to have compromised response to anti-IgM BCR cross-linking (18), we sought to examine whether the BCR signaling pathway of $\mathrm{p} 110 \delta^{\mathrm{D} 910 \mathrm{~A} / \mathrm{D} 910 \mathrm{~A}}$ mice remains unresponsive upon TCL1 overexpression. B cells from spleen or bone marrow of 2- to 4-month-old p110 $\delta^{\mathrm{WT} / \mathrm{WT} T C L 1}$ and $\mathrm{p} 110 \delta^{\mathrm{D} 910 \mathrm{~A} / \mathrm{D} 910 \mathrm{~T}} \mathrm{TCL} 1$ mice were subjected to varying durations of anti-IgM stimulation. Compared with $\mathrm{p} 110 \delta^{\mathrm{WT} / \mathrm{WT} T C L 1}$, B cells from $\mathrm{p} 110 \delta^{\mathrm{D} 910 \mathrm{~A} / \mathrm{D} 910 \mathrm{~A}}$ TCL1 mice showed significantly impaired AKT activation similar to what was previously reported in $\mathrm{p} 110 \delta^{\mathrm{D} 910 \mathrm{~A} / \mathrm{D} 910 \mathrm{~A}}$ mice (Figure 1, $A$ and $B$, and ref. 18). However, their changes in ERK1/2 and NF- $\mathrm{B}$ signaling were not as profound (Figure $1, \mathrm{~A}$ and $\mathrm{B}$, and Supplemental Figure 1, A and B; supplemental material available online with 
A

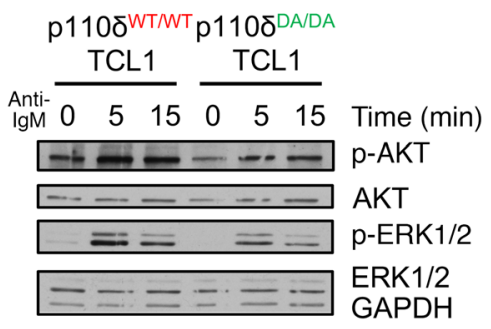

\section{B}

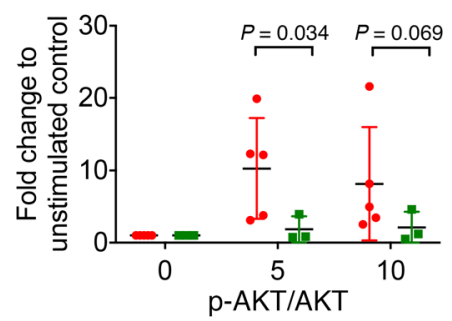

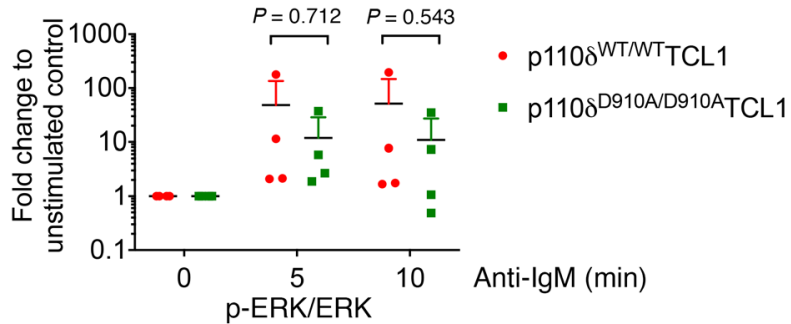

Figure 1. Global p110 $\delta$ kinase inactivation in E $\mu$-TCL1 mice partially impairs BCR signaling. B cells were purified from spleens or bone marrow of 4-monthold $\mathrm{p} 110 \delta^{\mathrm{WT} / \mathrm{WT} T C L 1}$ and $\mathrm{p} 110 \delta^{\mathrm{D910A} / \mathrm{Dg} 10 \mathrm{~A}} \mathrm{TCL} 1 \mathrm{mice}$ and stimulated with anti-lgM $(10 \mu \mathrm{g} / \mathrm{ml})$ for the indicated times. Cell lysates were immunoblotted for pATK ${ }^{5473}$ and total AKT. (A) The blots are representative of 4 independent experiments. (B) Densitometry analysis was conducted using Imagej analysis software $(\mathrm{NIH})$. All data were normalized to unstimulated control. Stimulated samples from 4 mice from each genotype were included for statistical analysis. ANOVA methods were used to compare condition means; data were log-transformed to stabilize variance. Bars represent mean \pm SD.

this article; https://doi.org/10.1172/JCI99386DS1). Similarly to p110 $\delta^{\mathrm{D} 910 \mathrm{~A} / \mathrm{D} 910 \mathrm{~A}}, \mathrm{~B}$ cells from $\mathrm{p} 110 \delta^{\mathrm{D} 910 \mathrm{~A} / \mathrm{D} 910 \mathrm{~A}} \mathrm{TCL} 1$ mice also exhibited impaired migration toward CXCL13 but not toward CXCL12 (Supplemental Figure 1C and ref. 55).

To understand the global effect of PI3K p1108 blockade in CLL pathogenesis in vivo, CLL disease development (presence of CD19/CD5-coexpressing cells in peripheral blood; ref. 45) was monitored in $\mathrm{p} 110 \delta^{\mathrm{WT} / \mathrm{WT}} \mathrm{TCL} 1, \mathrm{p} 110 \delta^{\mathrm{WT} / \mathrm{D} 910 \mathrm{~A}} \mathrm{TCL} 1$, and $\mathrm{p} 110 \delta^{\mathrm{D} 910 \mathrm{~A} / \mathrm{D} 910 \mathrm{~A}} \mathrm{TCL} 1 \mathrm{mice}$ by serial flow cytometry. The p110 $\delta^{\mathrm{WT} / \mathrm{WT} T C L 1}$ mice demonstrated leukemia $\left(\geq 10 \% \mathrm{CD} 19^{+} \mathrm{CD}^{+}\right.$ cells in the $\mathrm{CD}^{4} 5^{+}$population) in the blood at 5 months of age, with progressive expansion to over $80 \%$ of total lymphocytes by 7 months of age (Figure 2A). In contrast, leukemia cells in p1108 ${ }^{\mathrm{D} 910 \mathrm{~A} / \mathrm{D} 910 \mathrm{~A}} \mathrm{TCL} 1$ mice were absent in the blood, except in 1 mouse that showed disease onset at the age of 9 months (out of 19 mice tested at that age) (Figure 2, A and B). p110 $\delta^{\mathrm{WT} / \mathrm{D} 910 \mathrm{~A} T C L 1}$ mice did not appear to be different from p110 $\delta^{\mathrm{WT} / \mathrm{WT} T C L 1}$ mice in terms of disease development, time to leukemia, or overall survival (Supplemental Figure 2, A-C), and therefore were not included in the subsequent investigations. Splenomegaly was observed in the p110 $\delta^{\mathrm{WT} / \mathrm{WT} T C L 1}$ but not in the $\mathrm{p} 110 \delta^{\mathrm{D} 910 \mathrm{~A} / \mathrm{D} 910 \mathrm{~A}}$ TCL1 mice (Figure 2C). The leukemia burden in the spleen and bone marrow was also examined at 7, 9, and 11 months in separate mice and demonstrated that the majority of $\mathrm{p} 110 \delta^{\mathrm{D} 910 \mathrm{~A} / \mathrm{D} 910 \mathrm{~A}} \mathrm{TCL} 1$ mice were nearly devoid of disease in spleen and bone marrow (Figure 2D). A detailed autopsy study at 9 months of age demonstrated that only $30 \%$ of $\mathrm{p} 110 \delta^{\mathrm{D} 910 \mathrm{~A} / \mathrm{D} 910 \mathrm{~A}} \mathrm{TCL} 1$ mice had disease, which was limited to spleen only (Figure 2E). In contrast, all $\mathrm{p} 110 \delta^{\mathrm{WT} / \mathrm{WT} T C L 1}$ mice had histologic and/or gross evidence of lymphoid neoplasia in at least 1 of the organs, including spleen, lymph nodes, liver, kidney, and lung, and to a lesser extent in the heart and gastrointestinal tract (Figure 2E).

p1108 kinase inactivation leads to severe autoimmune phenotype in E $\mu$-TCL1 mice. Although p110 $\delta^{\mathrm{D} 910 \mathrm{~A} / \mathrm{D} 910 \mathrm{~T}} \mathrm{TCL} 1$ mice had significantly less leukemia burden, their median survival was 289 days, significantly shorter than the 394 days for $\mathrm{p} 110 \delta^{\mathrm{wT} / \mathrm{wT}}$ TCL1 mice $\left(P<0.001\right.$; Figure 3A). Similarly, p110 $\delta^{\mathrm{D} 910 \mathrm{~A} / \mathrm{D} 910 \mathrm{~A}}$ mice exhibited shortened median survival of 224 days compared with reported 800-day median survival of normal C57BL/6J (B6) mice (56). $\mathrm{p} 110 \delta^{\mathrm{D} 910 \mathrm{~A} / \mathrm{D} 910 \mathrm{~A}}$ mice have been previously described as developing spontaneous inflammatory bowel disease due to
Treg impairment in maintaining peripheral tolerance and altered macrophage function, leading to a hyperactivated innate inflammatory response (21). Similarly, we found that $\mathrm{p} 110 \delta^{\mathrm{D} 910 \mathrm{~A} / \mathrm{D} 910 \mathrm{~A}}$ and $\mathrm{p} 110 \delta^{\mathrm{D} 910 \mathrm{~A} / \mathrm{D} 910 \mathrm{~A}} \mathrm{TCL} 1 \mathrm{mice}$ showed evidence of neutrophilic and proliferative colitis occasionally with rectal prolapse and, to a lesser extent, enteritis and gastritis (Figure 3B).

Microenvironment p1108 kinase inactivation protects against CLL. While an overwhelming number of in vitro studies have focused on p1108 blockade in CLL B cells, little is known about the effect of p110 blockade on the microenvironment surrounding CLL or other disseminated leukemia models. Given that $\mathrm{p} 110 \delta^{\mathrm{D} 910 \mathrm{~A} / \mathrm{D} 910 \mathrm{~A}}$ mice are resistant to subcutaneous engraftment of solid tumors (31), we sought to determine whether systemic tumor dissemination was impacted. To do this, we examined whether genetic p1108 inactivation in the nonleukemic compartment is protective against disseminated leukemia. Leukemia cells from E $\mu$-TCL1 mice with functional p110 $\delta$ were adoptively transferred into recipient $110 \delta^{\mathrm{WT} / \mathrm{WT}}$ or p110 ${ }^{\mathrm{D} 910 \mathrm{~A} / \mathrm{D} 910 \mathrm{~A}}$ mice as previously described (57). Compared with $\mathrm{p} 110 \delta^{\mathrm{WT} / \mathrm{WT}}$ mice, $\mathrm{p} 110 \delta^{\mathrm{D} 910 \mathrm{~A} / \mathrm{D} 910 \mathrm{~A}}$ mice showed more resistance to leukemia development. p110 $\delta^{\mathrm{DP10A} / \mathrm{D} 910 \mathrm{~A}}$ mice had $20 \%$ reduced disease incidence ( 3 of 6 mice in p110 $8^{\mathrm{D} 910 \mathrm{~A} / \mathrm{D} 910 \mathrm{~A}}$ group vs. 7 of 10 mice in $\mathrm{p} 110 \delta^{\mathrm{WT} / \mathrm{WT}}$ group) (Figure $\left.4 \mathrm{~A}\right)$, a trend toward longer time to leukemia (median: $\mathrm{p} 110 \delta^{\mathrm{D} 910 \mathrm{~A} / \mathrm{D} 910 \mathrm{~A}}, 171$ days, vs. $\mathrm{p} 110 \delta^{\mathrm{WT} / \mathrm{WT}}, 24$ days; $P=0.215$ ) (Figure 4B), and lower peripheral disease burden (at day 31: $\mathrm{p} 110 \delta^{\mathrm{D} 910 \mathrm{~A} / \mathrm{D} 910 \mathrm{~A}}, 3.1 \%$ [SD $=1.2 \%$ ], vs. $\mathrm{p} 110 \delta^{\mathrm{WT} / \mathrm{WT}}, 29.7 \%$ [SD $=21.7 \%]$; Figure $4 \mathrm{C}$ ). When this observation was repeated with a 4 -fold greater number of tumor cells $\left(2 \times 10^{7}\right), \mathrm{p} 110 \delta^{\mathrm{D} 910 \mathrm{~A} / \mathrm{D} 910 \mathrm{~A}}$ mice developed a level of leukemia similar to that of the $\mathrm{p} 110 \delta^{\mathrm{WT} / \mathrm{WT}}$ mice on day $7(74.4 \%$ [SD $=6.5 \%]$ and $79.6 \%[\mathrm{SD}=3.6 \%]$, respectively; Figure $4 \mathrm{D}$ ), but were found to spontaneously regress on day 14, with 12 of 19 mice completely clearing their leukemia by day 21 (Figure 4D). The peripheral blood disease in the completely recovered $\mathrm{p} 110 \delta^{\mathrm{D} 910 \mathrm{~A} / \mathrm{D} 910 \mathrm{~A}}$ mice $\left(\mathrm{p} 110 \delta^{\mathrm{D} 910 \mathrm{~A} / \mathrm{D} 910 \mathrm{~A}}-\mathrm{CR}\right)$ remained low for the rest of the study, and spleen examination showed no signs of splenomegaly. On the contrary, the $\mathrm{p} 110 \delta^{\mathrm{WT} / \mathrm{WT}}$ mice continued to progress until they reached a moribund state starting on day 49 .

To further assess whether an antitumor immunologic response was present, on day 64 after the first transfer, $\mathrm{p} 110 \delta^{\mathrm{D} 910 \mathrm{~A} / \mathrm{D} 910 \mathrm{~A}}-\mathrm{CR}$ mice were rechallenged with the original $\mathrm{E} \mu$-TCL1 donor to assess for an adaptive memory response. Wild-type naive mice were included as a positive control for successful adoptive transfer. For 
A

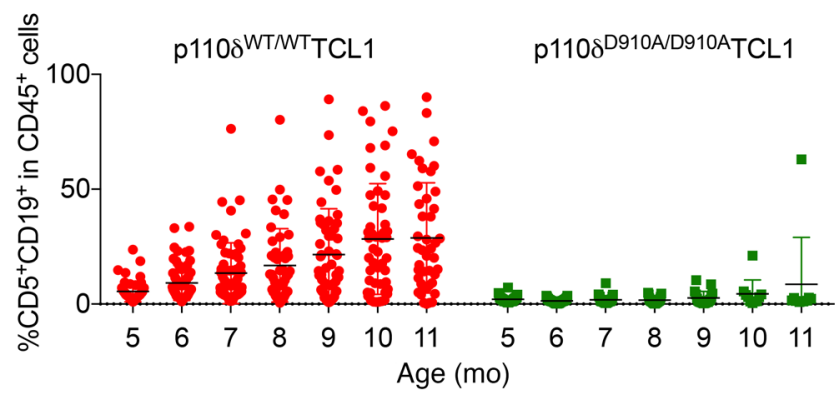

B

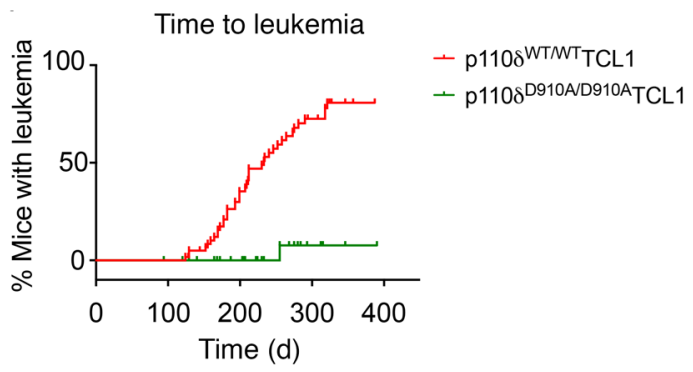

c

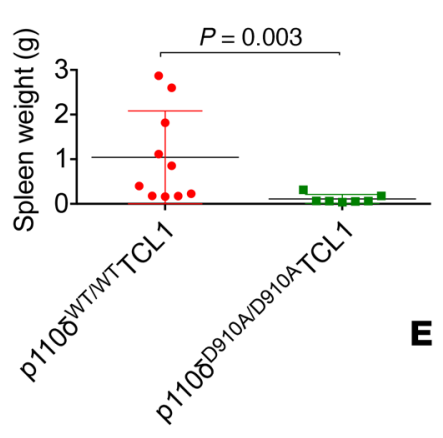

E
D

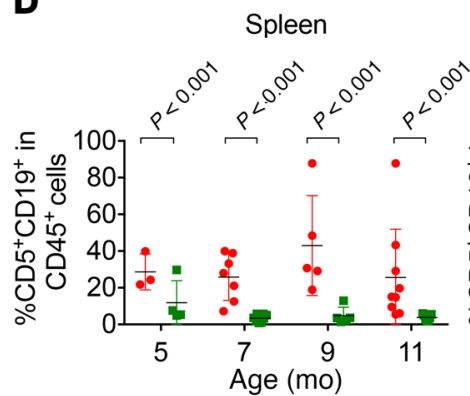

\begin{tabular}{c} 
Bone marrow \\
\hline$\rho^{0^{0^{A}}}$
\end{tabular}

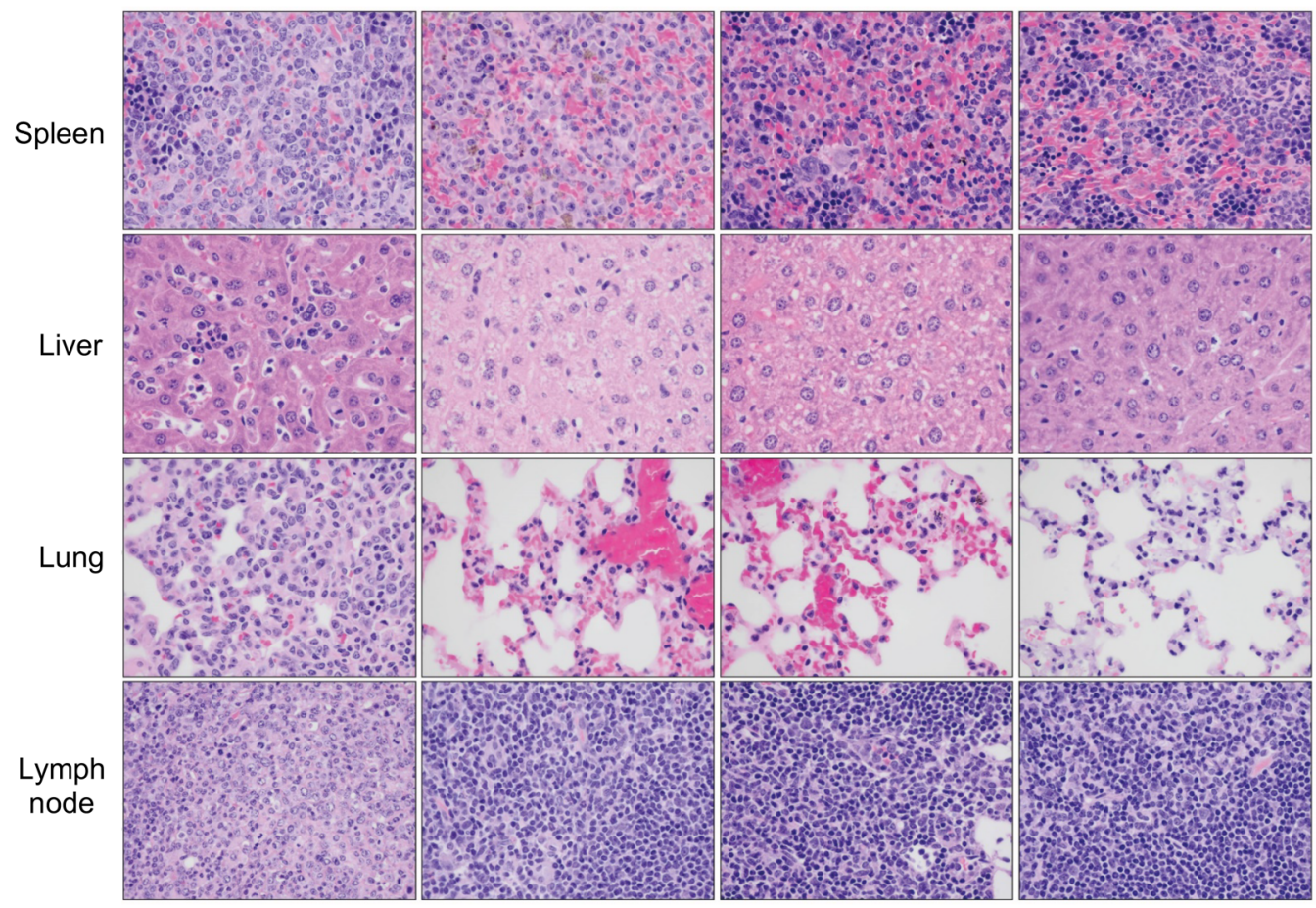

Figure 2. Global p110 $\delta$ kinase inactivation delays spontaneous leukemia development. (A) p110 $\delta^{\mathrm{WT} / \mathrm{WT} T C L 1}(n=43-65)$ and $\mathrm{p} 110 \delta{ }^{\mathrm{D} 910 \mathrm{~A} / 0910 \mathrm{~A}} \mathrm{TCL} 1(n=9-39)$ mice were monitored monthly for leukemia development through immunophenotyping of $\mathrm{CD}^{+} \mathrm{CD}^{+} 9^{+}$cells in the peripheral blood by flow cytometry. (B)

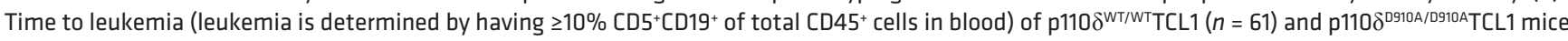
( $n=44$ ). (Log-rank test $P<0.001$.) (C) Spleen weight from 9-month-old $p 110 \delta^{\mathrm{WT} / W T} T C L 1$ and $p 110 \delta^{\mathrm{D} 910 \mathrm{~A} / \mathrm{D910A} T C L 1}$ mice. (Wilcoxon rank sum test $P=0.003$.) (D) Lymphocytes from spleen and bone marrow were obtained from p110 $\delta^{\mathrm{WT} / \mathrm{WT} T C L 1}(n=3-10)$ and p110 $\delta^{\mathrm{D910A} / 0910 \mathrm{~A} T C L 1}$ mice $(n=4-11) 5,7,9$, and 11 months of age. $\mathrm{CD}^{+} \mathrm{CD} 19+$ cells were examined by flow cytometry. (Group comparisons from mixed-effects models using log-transformed data. $P$ values within each organ were adjusted for multiple comparisons using Holm's procedure.) Bars represent mean \pm SD. (E) Histology of spleen, liver, and lung from p110 $\delta^{\mathrm{WT} / \mathrm{WT}} \mathrm{TCL} 1(n=10)$ and $\mathrm{p} 110 \delta^{\mathrm{Dg10A} / \mathrm{D910A}} \mathrm{TCL} 1$ mice $(n=10)$ at 9 months of age. Original magnification, $\times 60$. 
$\mathbf{A}$

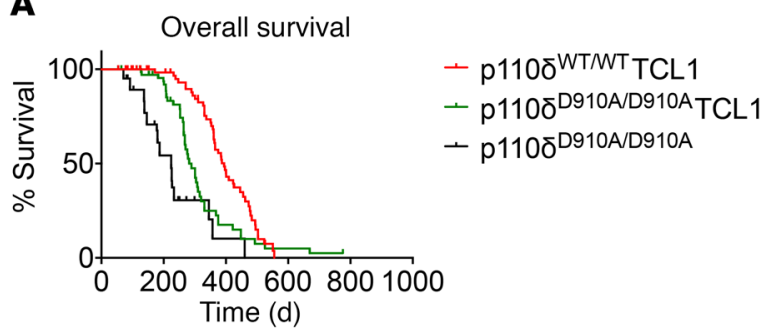

B
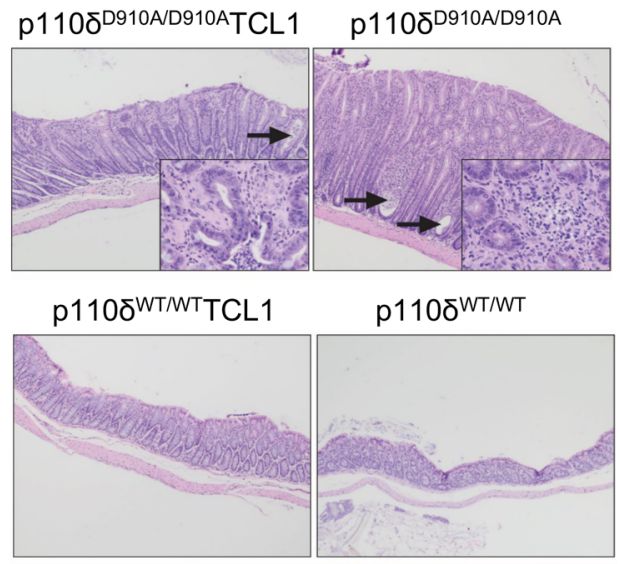

Figure 3. p110 $\delta$ kinase inactivation leads to severe autoimmune phenotype in EH-TCL1 mice. (A) Overall survival of p110 $\delta^{\mathrm{WT} / \mathrm{WT} T C L 1}(n=88)$ and p110 $\delta^{0910 A / 0910 A} T C L 1$ mice $(n=79)$. (Log-rank test $P<0.001$.) (B) Histology

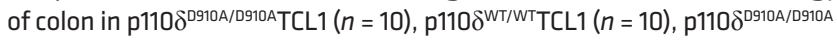
$(n=10)$, and p110 $\delta^{\mathrm{WT} / \mathrm{WT}}(n=10)$ mice at 9 months of age. Both p110 $\delta^{\text {D910A/D910A }}$ TCL1 and p110 $\delta^{\text {D910A/D910A }}$ demonstrated severe colitis, consisting of hyperplasia of the crypt epithelium, crypt abscesses (arrows), and numerous neutrophils within the lamina propria (inset). Colitis was not observed in p110 $\delta^{\mathrm{WT} / \mathrm{WT} T C L 1}$ and $\mathrm{p} 110 \delta^{\mathrm{WT} / \mathrm{WT}}$ mice. Original magnification, $\times 20$; inset, $\times 40$.

the first rechallenge, wild-type naive mice developed $63.4 \%$ (SD = $9.9 \%$ ) leukemia in the blood by day 14 , whereas $110 \delta^{\mathrm{D} 910 \mathrm{~A} / \mathrm{D} 910 \mathrm{~A}}-\mathrm{CR}$ mice showed no sign of blood disease throughout the course of the experiment (Figure 4E). Day 50 after rechallenge, p110 $\delta^{\mathrm{D} 910 \mathrm{~A} / \mathrm{D} 910 \mathrm{~A}}$ CR mice were challenged again with a different E $\mu$-TCL1 leukemia donor. During the second rechallenge, wild-type naive mice developed $48.4 \%$ ( $\mathrm{SD}=10.4 \%$ ) leukemia in the blood by day 27 , while $\mathrm{p} 110 \delta^{\mathrm{D} 910 \mathrm{~A} / \mathrm{D} 910 \mathrm{~A}}-\mathrm{CR}$ mice again rejected the disease (Figure $4 \mathrm{~F}$ ).

p110 $\delta$ kinase inactivation impedes leukemia via a T cell-dependent mechanism. Interestingly, the $\mathrm{p} 110 \delta^{\mathrm{D} 910 \mathrm{~A} / \mathrm{D} 910 \mathrm{~A}}$ mice that had leukemia regression and resisted rechallenge (Figure 4, E and F) showed expanded $\mathrm{CD} 44^{+} \mathrm{CD} 4^{+}$and $\mathrm{CD} 44^{+} \mathrm{CD} 8^{+} \mathrm{T}$ cells immediately after rechallenge (Figure 5, $\mathrm{A}$ and $\mathrm{B}$ ). These data suggest that the leukemia resistance may be $\mathrm{T}$ cell mediated. Therefore, we sought to examine the dependence of leukemia resistance on $\mathrm{CD}^{+}$and $\mathrm{CD}^{+} \mathrm{T}$ cells in p110 $\delta^{\mathrm{D} 910 \mathrm{~A} / \mathrm{D} 910 \mathrm{~A}}$ mice. $\mathrm{p} 110 \delta^{\mathrm{D} 910 \mathrm{~A} / \mathrm{D} 910 \mathrm{~A}}$ mice were engrafted with leukemia and subjected to $\mathrm{CD} 4^{+}$or $\mathrm{CD} 8^{+} \mathrm{T}$ cell depletion. Confirmation of $\mathrm{CD}^{+}$or $\mathrm{CD}^{+}$depletion and blood disease burden were examined weekly (Supplemental Figure 3A). Day 17 after engraftment, $\mathrm{p} 110 \delta^{\mathrm{D} 910 \mathrm{~A} / \mathrm{D} 910 \mathrm{~A}}$ mice that received corresponding isotype control developed leukemia significantly more slowly than $\mathrm{p} 110 \delta^{\mathrm{WT} / \mathrm{WT}}$ mice as previously observed, whereas $\mathrm{CD}^{+}$or $\mathrm{CD}^{+}$depletion resulted in higher disease burden, to a level equivalent to that of $\mathrm{p} 110 \delta^{\mathrm{WT} / \mathrm{WT}}$ mice (Figure 5C and Supplemental Figure 3, B and C). Upon euthanizing at day 37 , higher splenic disease was found in both the CD4 ${ }^{+}$ and the $\mathrm{CD}^{+}$depleted groups (Figure 5D). However, only $\mathrm{CD} 8^{+}$ depletion resulted in higher disease in the bone marrow (Figure 5D).

To further investigate the different roles played by $\mathrm{CD} 4^{+}$and $\mathrm{CD}^{+} \mathrm{T}$ cells, recombination activating gene 1-knockout $\left(\mathrm{RAG}^{-/}\right)$ mice were reconstituted with $\mathrm{CD}^{+}, \mathrm{CD}^{+}$, and $\mathrm{CD}^{+} \mathrm{T}$ cells from $\mathrm{p} 110 \delta^{\mathrm{WT} / \mathrm{WT}}$ and $\mathrm{p} 110 \delta^{\mathrm{D} 910 \mathrm{~A} / \mathrm{D} 910 \mathrm{~A}}$ mice followed by E $\mu$-TCL1 leukemia engraftment. E $\mu$-TCL1 engraftment without T cell reconstitution was included as positive control. $\mathrm{T}$ cell population and leukemia burden were examined by flow cytometry (Supplemental Figure 4, A, E, and F). Day 21 after leukemia engraftment, both the $\mathrm{p} 110 \delta^{\mathrm{WT} / \mathrm{WT}}-\mathrm{CD}^{+}$group and the $\mathrm{p} 110 \delta^{\mathrm{D} 910 \mathrm{~A} / \mathrm{D} 910 \mathrm{~A}}-\mathrm{CD}^{+}$group showed less disease compared with the no-T cell group (Supplemental Figure 4A). For both $\mathrm{p} 110 \delta^{\mathrm{WT} / \mathrm{WT}}$ and $\mathrm{p} 110 \delta^{\mathrm{D} 910 \mathrm{~A} / \mathrm{D} 910 \mathrm{~A}}$, the $\mathrm{CD}^{+} \mathrm{T}$ cell group had variable disease outcome, while the $\mathrm{CD} 8^{+}$ $\mathrm{T}$ cell group had the least amount of disease compared with the $\mathrm{T}$ cell counterparts of the same genotype (Supplemental Figure 4A). When the differences between the 2 genotypes are compared, it appears that both $\mathrm{p} 110 \delta^{\mathrm{D} 910 \mathrm{~A} / \mathrm{D} 910 \mathrm{~A}} \mathrm{CD}^{+}$and $\mathrm{CD} 8^{+} \mathrm{T}$ cells led to less disease compared with their wild-type counterparts (Supplemental Figure 4, B-D).

p110 $\delta$ kinase inactivation results in fewer antigen-experienced $T$ cells. To further elucidate the role of $\mathrm{CD}^{+}$and $\mathrm{CD}^{+} \mathrm{T}$ cells in leukemia resistance of $\mathrm{p} 110 \delta^{\mathrm{D} 910 \mathrm{~A} / \mathrm{D} 910 \mathrm{~A}}$ mice, the effector and memory kinetics of these cells were examined in the context of leukemia regression. Disease regression in $\mathrm{p} 110 \delta^{\mathrm{D} 910 \mathrm{~A} / \mathrm{D} 910 \mathrm{~A}}$ mice was recreated using secondary leukemia cells from $\mathrm{p} 110 \delta^{\mathrm{WT} / \mathrm{WT}}$ mice previously engrafted as shown in Figure 4D. On day 14, among the 30 enrolled mice per group, 6 mice of the lowest and highest blood disease burden from each group were euthanized for further analysis. The mice with the highest and lowest disease burden from the $110 \delta^{\mathrm{WT} / \mathrm{WT}}$ group showed very similar levels of leukemia $(80 \%[\mathrm{SD}=4.3 \%]$ vs. $85 \%[\mathrm{SD}=1.1 \%])$ in the blood. In contrast, the 6 mice with lowest disease burden in the $\mathrm{p} 110 \delta^{\mathrm{D} 910 \mathrm{~A} / \mathrm{D} 910 \mathrm{~A}}$ group resisted disease $(40 \%$ [SD $\left.=13.6]\right)$, and the 6 mice with highest disease burden did not ( $85 \%$ [SD $=2.5 \%]$ ) (Figure 6A). Therefore, $12 \mathrm{p} 110 \delta^{\mathrm{WT} / \mathrm{WT}}$ mice were assigned into 1 group $\left(\mathrm{p} 110 \delta^{\mathrm{WT} / \mathrm{WT}}\right)$, and $\mathrm{p} 110 \delta^{\mathrm{D} 910 \mathrm{~A} / \mathrm{D} 910 \mathrm{~A}}$ were designated into responder $\left(\mathrm{p} 110 \delta^{\mathrm{D} 910 \mathrm{~A} / \mathrm{D} 910 \mathrm{~A}}-\mathrm{R}\right)$ and nonresponder $\left(\mathrm{p} 110 \delta^{\mathrm{D} 910 \mathrm{~A} / \mathrm{D} 910 \mathrm{~A}}-\mathrm{NR}\right)$ groups, respectively.

In agreement with a previous report (58), both $\mathrm{CD} 4^{+}$and $\mathrm{CD} 8^{+}$ T cells expanded in $\mathrm{p} 110 \delta^{\mathrm{WT} / \mathrm{WT}}$ mice, whereas they either remained the same or showed a slight decrease in the $\mathrm{p} 110 \delta^{\mathrm{D} 910 \mathrm{~A} / \mathrm{D} 910 \mathrm{~A}}-\mathrm{R}$ mice (Figure 6, B and C). The frequency of effector $\left(\mathrm{CD} 44^{\mathrm{hi}} \mathrm{CD} 62 \mathrm{~L}^{\mathrm{lo}}\right)$ and memory $\left(\mathrm{CD} 44^{\text {hi }} \mathrm{CD} 62 \mathrm{~L}^{\text {hi }}\right) \mathrm{CD}^{+}$and $\mathrm{CD} 8^{+} \mathrm{T}$ cells expanded in all groups at varying degrees (Figure 6, D-G). Gating strategy is in included in Supplemental Figure 5. The degree of expansion in effector $\left(C D 44^{\text {hi }}\right.$ CD $\left.62 \mathrm{~L}^{\mathrm{lo}}\right) \mathrm{CD} 4^{+} \mathrm{T}$ cells did not differ among the groups (Figure 6D), whereas effector $\left(\mathrm{CD} 44^{\mathrm{hi}} \mathrm{CD} 62 \mathrm{~L}^{\mathrm{lo}}\right) \mathrm{CD}^{+} \mathrm{T}$ cells expanded to a higher degree in $\mathrm{p} 110 \delta^{\mathrm{D} 910 \mathrm{~A} / \mathrm{D} 910 \mathrm{~A}}-\mathrm{R}$ mice, suggesting the potential role of effector $\mathrm{CD}^{+} \mathrm{T}$ cells in disease clearance (Figure 6E). On the other hand, memory $\left(\mathrm{CD} 44^{\mathrm{hi}} \mathrm{CD} 62 \mathrm{~L}^{\mathrm{hi}}\right)$ $\mathrm{CD}^{+} \mathrm{T}$ cells expanded to a higher degree in $\mathrm{p} 110 \delta^{\mathrm{WT} / \mathrm{WT}}$ and p110 $\delta^{\mathrm{D} 910 \mathrm{~A} / \mathrm{D} 910 \mathrm{~A}}-\mathrm{NR}$ diseasedmice (Figure 6F), whichlikelyassociates with disease burden. In contrast, the expansion of memory (CD $44^{\text {hi }}$ CD62 $\mathrm{L}^{\text {hi }}$ ) $\mathrm{CD}^{+} \mathrm{T}$ cells does not seem to correlate with genotype or disease burden (Figure 6G). 
A

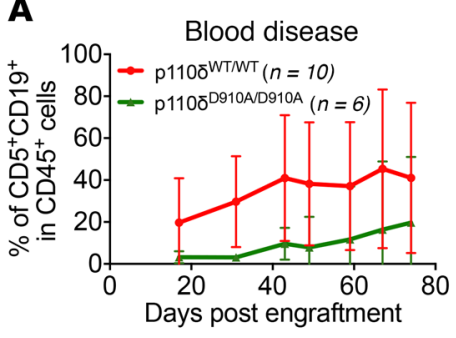

B

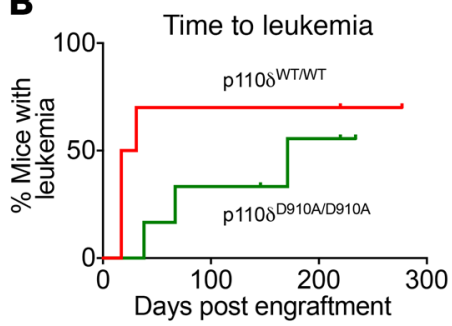

C

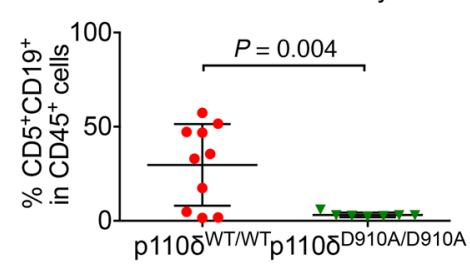

D

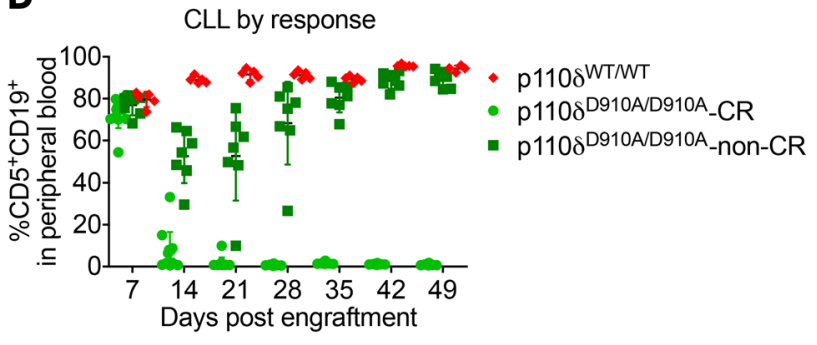

E

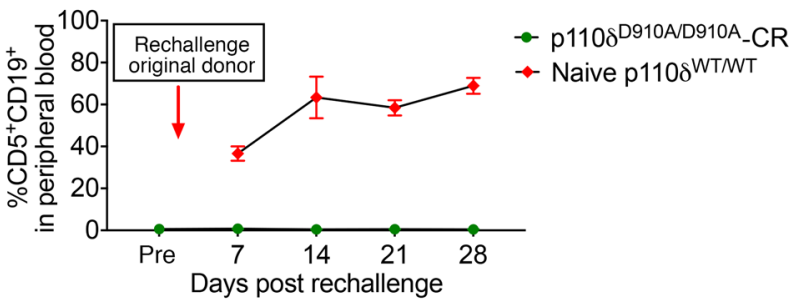

$\mathbf{F}$

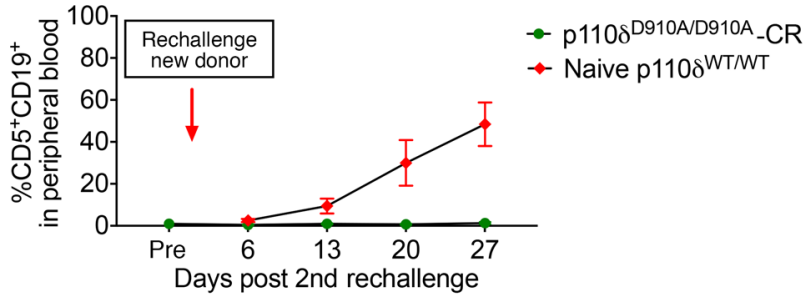

Figure 4. Microenvironment $\mathbf{p} 110 \delta$ kinase inactivation protects against CLL. $(\mathbf{A}-\mathbf{C}) \mathrm{p} 110 \delta^{\mathrm{WT} / \mathrm{WT}}(n=10)$ and $\mathrm{p} 110 \delta^{\mathrm{Dg} 10 \mathrm{~A} / \mathrm{Dg} 10 \mathrm{~A}}$ mice $(n=6)$ were engrafted with $5 \times 10^{6} \mathrm{E} \mu-\mathrm{TCL} 1$ leukemia cells through tail vein injection. Peripheral blood disease was monitored through immunophenotyping of CD5 ${ }^{+} \mathrm{CD} 19^{+}$cells by flow cytometry. (A) Average weekly blood disease burden. Each data point represents mean \pm SD. (B) Time to leukemia (leukemia is determined by having $\geq 10 \% \mathrm{CDF}^{+} \mathrm{CD} 19^{+}$of total CD45+ cells in blood) of $\mathrm{p} 110 \delta^{\mathrm{WT} / \mathrm{WT}}$ and $\mathrm{p} 110 \delta^{\mathrm{D910A} / \mathrm{Dg} 10 \mathrm{~A}}$ mice. (Log-rank test $P=0.215$.) (C) Individual blood disease on day 31 . Bars represent mean $\pm \mathrm{SD}$. $\left(P=0.004\right.$ based on 2 -sample $t$ test with unequal variances.) $(\mathbf{D}-\mathbf{F})$ p110 $\delta^{\mathrm{WT} / \mathrm{WT}}(n=10)$ and p110 $\delta^{\mathrm{Dg} 10 \mathrm{~A} / \mathrm{Dg} 10 \mathrm{~A}}$ mice $(n=7)$ were engrafted with $5 \times 10^{6} \mathrm{E} \mu$-TCL1 leukemia cells through tail vein injection. Peripheral blood disease was monitored through immunophenotyping of CD5 ${ }^{+} \mathrm{CD} 19^{+}$cells by flow cytometry. (D) $110 \delta^{\mathrm{WT} / \mathrm{WT}}(n=5)$ and $\mathrm{p} 110 \delta^{\mathrm{D910A} / 0910 \mathrm{~A}}$ mice $(n=19)$ underwent adoptive transfer of $2 \times 10^{7}$ E $\mu$-TCL1 leukemia cells. Blood disease was monitored weekly by flow cytometry. Bars represent mean \pm SD. (E) Sixty-three days after the first transfer, p110 $\delta^{0910 \mathrm{~A} / 0910 \mathrm{~A}}$ mice that had regressed disease $(n=10)$ and naive p110 $\delta^{\text {WT/WT }}(n=5)$ were challenged with $2 \times 10^{7}$ leukemic cells of the same donor E $\mu$-TCL1 cells. Each data point represents mean \pm SD. (F) Forty-two days after the second transfer, the remaining $\mathrm{p}^{110} \delta^{\mathrm{Dg} 10 \mathrm{~A} / \mathrm{Dg} 10 \mathrm{~A}}(n=9)$ and new naive $\mathrm{p} 110 \delta^{\mathrm{WT} / \mathrm{WT}}(n=5)$ mice were challenged with $2 \times 10^{7}$ leukemic cells from a different $\mathrm{E} \mu-\mathrm{TCL} 1$ donor. Each data point represents mean $\pm \mathrm{SD}$.

p110 $\delta$ kinase inactivation results in fewer antigen-specific CD8 ${ }^{+}$ $T$ cells. To further examine the effect of p1108 inhibition on the development or recruitment of antigen-specific antitumor $\mathrm{CD} 8^{+} \mathrm{T}$ cells, MHC I ovalbumin-expressing E $\mu$-TCL1 (OVA-TCL1) leukemia cells were engrafted into $\mathrm{p} 110 \delta^{\mathrm{WT} / \mathrm{WT}}$ and $\mathrm{p} 110 \delta^{\mathrm{D} 910 \mathrm{~A} / \mathrm{D} 910 \mathrm{~A}}$ mice. Tumor-infiltrating OVA-specific CD8 ${ }^{+} \mathrm{T}$ cells in the blood were examined weekly using a fluorescent tetramer recognizing MHC I specific for OVA antigen. Paradoxically, p110 ${ }^{\mathrm{D} 910 \mathrm{~A} / \mathrm{D} 910 \mathrm{~A}}$ mice had diminished $\mathrm{OVA}^{+} \mathrm{CD} 8^{+} \mathrm{T}$ cells as compared with $\mathrm{p} 110 \delta^{\mathrm{WT} / \mathrm{WT}}$ mice (Figure 6H and Supplemental Figure 6).

p110 $\delta$ kinase inactivation reverses immune suppression in leukemia mice. Effective antitumor immunity is often suppressed by immune checkpoint molecules and/or Tregs (59). $\mathrm{p} 110 \delta^{\mathrm{D} 910 \mathrm{~A} / \mathrm{D} 910 \mathrm{~A}}$ mice were reported to have impaired Treg suppression that unleashes $\mathrm{CD}^{+}$ cytotoxic $\mathrm{T}$ cells in solid tumor-bearing mice (31). Given that p110 ${ }^{\mathrm{D} 910 \mathrm{~A} / \mathrm{D} 910 \mathrm{~A}}$ mice resist leukemia despite compromised antigenspecific $\mathrm{CD} 8^{+}$response, we sought to examine the immune-suppressive profile of $\mathrm{p} 110 \delta^{\mathrm{D} 910 \mathrm{~A} / \mathrm{D} 910 \mathrm{~A}}$ mice in the context of leukemia.
$\mathrm{T}$ cell defects in CLL are characterized by the exhausted phenotype, overexpression of checkpoint molecules, and decreased effector function $(9,41,42)$. At 11 months of age, $\mathrm{p} 110 \delta^{\mathrm{D} 910 \mathrm{~A} / \mathrm{D} 910 \mathrm{~A}}$ TCL1 mice showed significantly fewer CTLA $4^{+} \mathrm{CD} 4^{+}$and PD-1 ${ }^{+}$ $\mathrm{CD}^{+} \mathrm{T}$ cells compared with $\mathrm{p} 110 \delta^{\mathrm{WT} / \mathrm{WT} T C L} 1$ mice (Figure 7A). However, the lack of immune checkpoint molecule expression could be due to the lower disease burden. We therefore examined blood and spleen samples from preleukemic 5-month-old mice. $\mathrm{p} 110 \delta^{\mathrm{WT} / \mathrm{WT} T C L 1}$ mice still expressed a higher frequency of $\mathrm{PD}-1^{+} \mathrm{CD} 4^{+} \mathrm{T}$ cells in the spleen, despite similar leukemia burden (Figure 7B and Supplemental Figure 7A). To better isolate the T cell effect, these markers were examined in the adoptive transfer study shown in Figure 4D. Immediately after engraftment on day 7 , $\mathrm{p} 110 \delta^{\mathrm{D} 910 \mathrm{~A} / \mathrm{D} 910 \mathrm{~A}}$ mice showed a higher frequency of CTLA $4^{+} \mathrm{CD} 4^{+}$ and $\mathrm{PD}-1^{+} \mathrm{CD} 4^{+} \mathrm{T}$ cells (Supplemental Figure $7 \mathrm{~B}$ ). However, from day 14 and throughout the disease course, the frequency of $\mathrm{CTLA} 4^{+} \mathrm{CD} 4^{+}$and $\mathrm{PD}-1^{+} \mathrm{CD} 4^{+} \mathrm{T}$ cells correlated with disease burden in both $\mathrm{p} 110 \delta^{\mathrm{WT} / \mathrm{WT}}$ and $\mathrm{p} 110 \delta^{\mathrm{D} 910 \mathrm{~A} / \mathrm{D} 910 \mathrm{~A}}$ mice, as seen in 

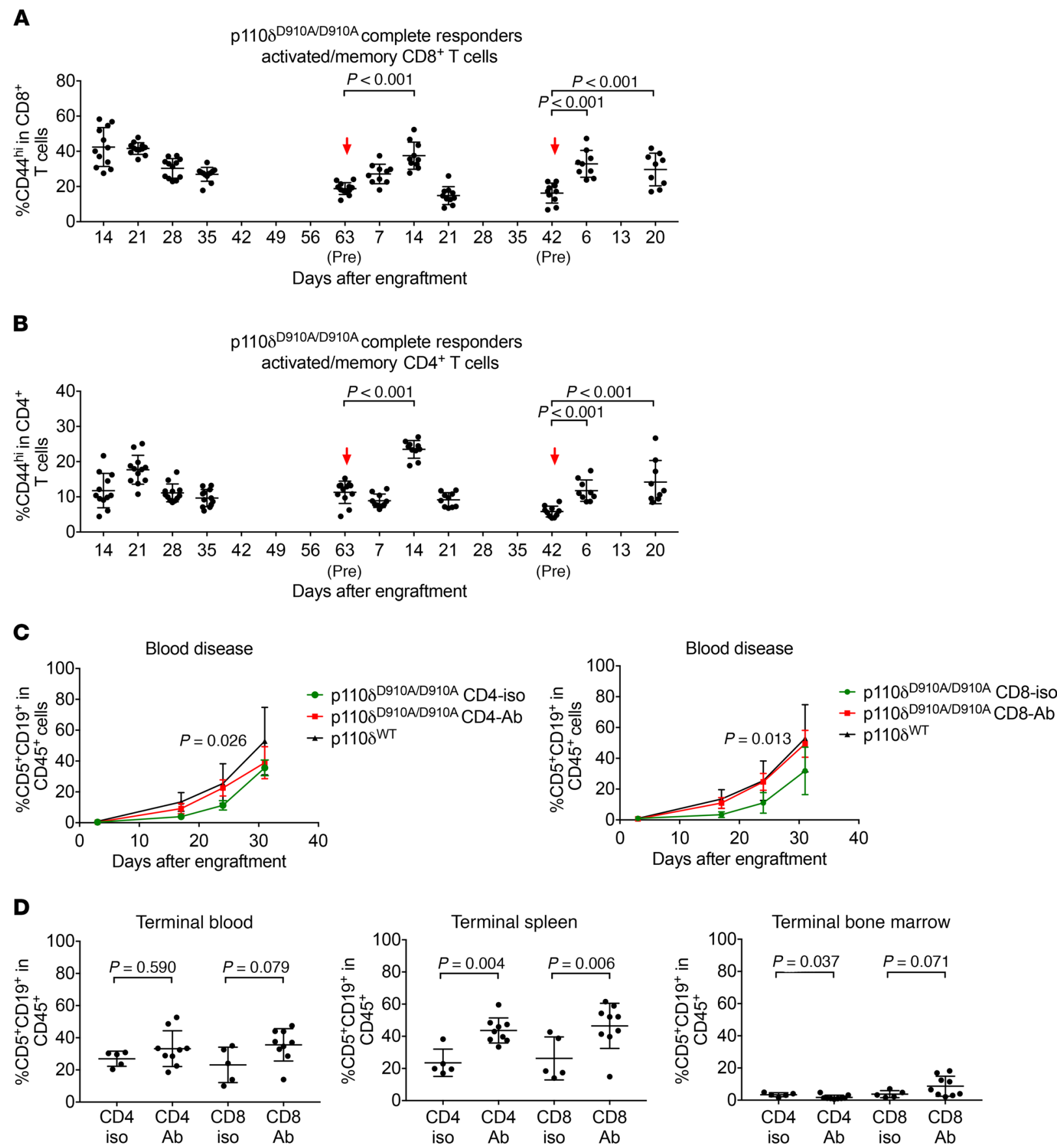

Figure 5. p110 $\delta$ kinase inactivation resists leukemia through a T cell-dependent mechanism. (A and $\mathbf{B}) \mathrm{CD} 44^{+} \mathrm{CD} 4^{+}(\mathbf{A})$ and $C D 44^{+} \mathrm{CD} 8^{+}(\mathbf{B}) \mathrm{T}_{\text {cells }}$ were examined in mice from Figure 3, D-F. Bars represent mean \pm SD. Arrow denotes adoptive transfer of leukemia cells. A repeated-measures model was applied to the log-transformed data. For the first rechallenge, comparisons were made of day 7 and day 14 after rechallenge versus before rechallenge. For the second rechallenge, comparisons were made of day 6 and day 20 after rechallenge versus before rechallenge. (C) E $\mu$-TCL1 leukemia cells were adoptively transferred into $\mathrm{p} 110 \delta^{\mathrm{WT} / \mathrm{WT}}(n=5)$ and $\mathrm{p} 110 \delta^{\mathrm{D910A} / \mathrm{D910A}}$ mice. $\mathrm{p} 110 \delta^{\mathrm{Dg} 10 \mathrm{~A} / \mathrm{D910A}}$ mice were subjected to CD4-depleting $(n=9)$ or CD8-depleting $(n=9)$ antibody injections once every 3 days. Isotype controls (CD4 isotype $n=5$, CD8 isotype $n=5$ ) were included as controls. Group differences were estimated using

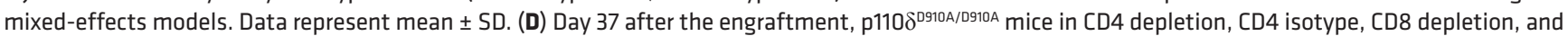
CD8 isotype groups were euthanized. Spleen, bone marrow, and blood were analyzed for CD5+CD19+ leukemia cells. Bars represent mean \pm SD. (Differences between antibody and corresponding isotype control groups were estimated using ANOVA based on the log-transformed data.)

Figure 4D. A similar correlation was also found in the adoptive transfer study shown in Figure 6.

$\mathrm{CD} 4^{+} \mathrm{CD} 25^{+} \mathrm{FoxP}^{+}$Tregs from blood and spleen of $\mathrm{p} 110 \delta^{\mathrm{WT} / \mathrm{WT}}$ TCL1 and p110 $\delta^{\mathrm{DP10A} / \mathrm{D} 910 \mathrm{~A}} \mathrm{TCL} 1$ mice were examined at 9 months of age. p110 ${ }^{\mathrm{D} 910 \mathrm{~A} / \mathrm{D} 910 \mathrm{~A}} \mathrm{TCL} 1$ exhibited significantly fewer Tregs compared with $\mathrm{p} 110 \delta^{\mathrm{WT} / \mathrm{WT} T C L 1}$ mice (Figure $7 \mathrm{C}$ ). Splenic Tregs were also examined in naive and postengraftment $\mathrm{p} 110 \delta^{\mathrm{WT} / \mathrm{WT}}$ and $\mathrm{p} 110 \delta^{\mathrm{D} 910 \mathrm{~A} / \mathrm{D} 910 \mathrm{~A}}$ mice, as shown in Figure 4D. Tregs were 
A

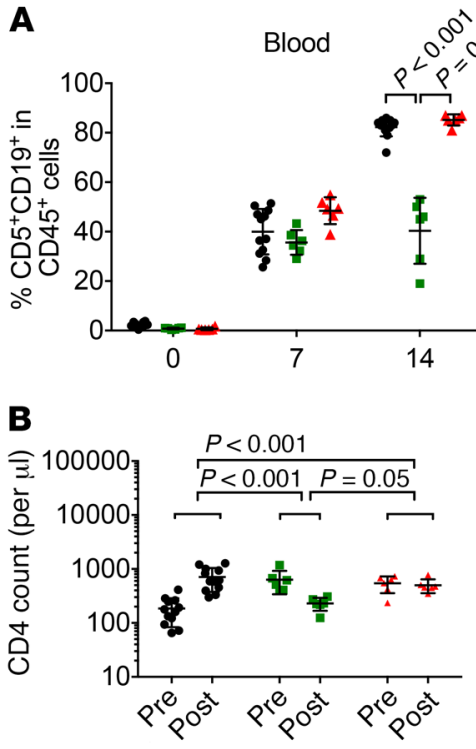

D
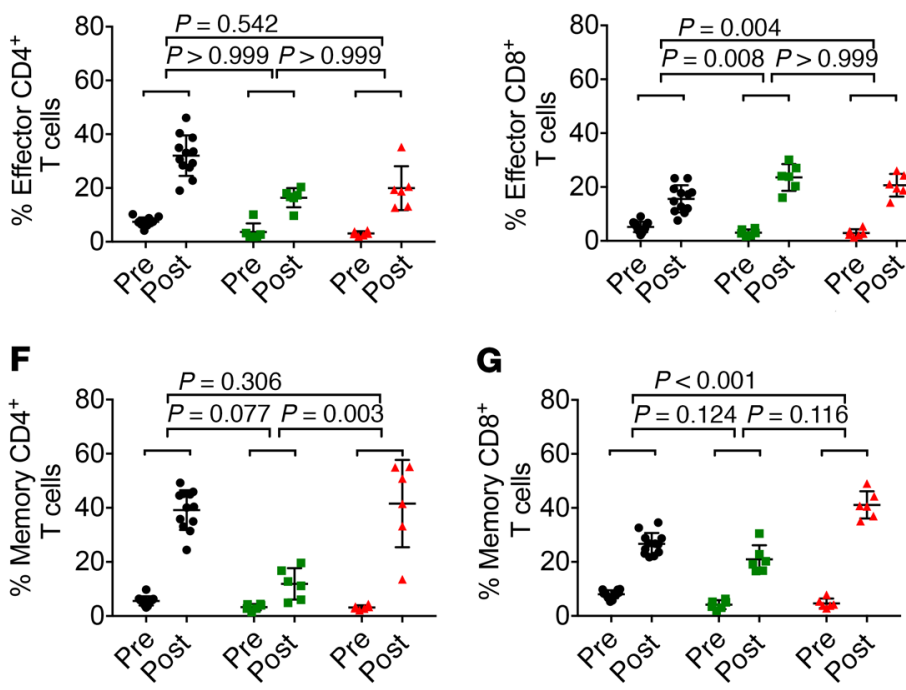

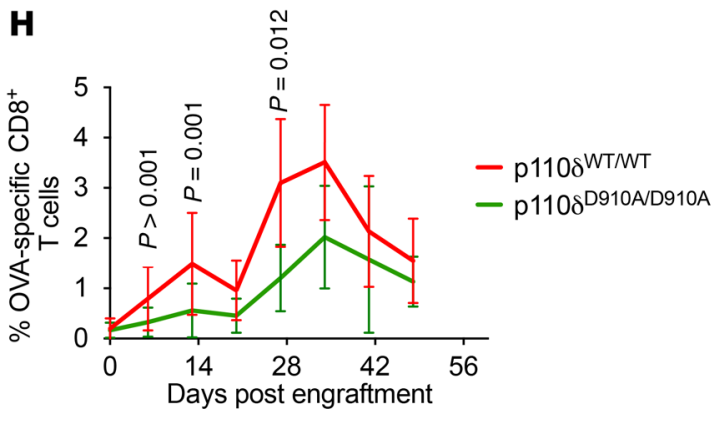

found to be higher in $\mathrm{p} 110 \delta^{\mathrm{WT} / \mathrm{WT}}$ mice before engraftment and significantly expanded after engraftment (Figure 7D). However, they were lower in $\mathrm{p} 110 \delta^{\mathrm{D} 910 \mathrm{~A} / \mathrm{D} 910 \mathrm{~A}}$ mice before engraftment and either remained the same in mice that regressed or slightly expanded in mice that progressed on disease (Figure 7D). To examine whether the Tregs were functionally impaired in p110 $8^{\mathrm{D} 910 \mathrm{~A} / \mathrm{D} 910 \mathrm{~A}}$ mice, splenic $\mathrm{CD} 4^{+} \mathrm{CD} 25^{+} \mathrm{T}$ cells were purified from $\mathrm{p} 110 \delta^{\mathrm{WT} / \mathrm{WT}}$ and $\mathrm{p} 110 \delta^{\mathrm{D} 910 \mathrm{~A} / \mathrm{D} 910 \mathrm{~A}}$ mice at baseline and
Figure 6. Impact of p110 $\delta$ inactivation on T cell antileukemia response. $\mathrm{p} 110 \delta^{\mathrm{WT} / \mathrm{WT}}$ and $\mathrm{p} 110 \delta^{\mathrm{D910A/D910A}}$ mice after adoptive transfer with $2 \times 10^{7}$ secondary E $\mu$-TCL1 leukemia cells. (A) Percentage $\mathrm{CD} 5^{+} \mathrm{CD} 19^{+}$of $\mathrm{CD} 45^{+}$cells was examined by flow cytometry on days 0 , 7, and 14. (B-C) Absolute number of CD4 ${ }^{+} T$ cells (B), absolute number of $C D 8^{+} T$ cells (C), effector CD4 ${ }^{+} T$ cells (percentage CD44 ${ }^{\circ} \mathrm{CD} 62 \mathrm{~L}^{\text {hi }} \mathrm{CD} 4^{+}$ of $\mathrm{CD} 4^{+}$cells) (D), effector $\mathrm{CD} 8^{+} \mathrm{T}$ cells (percentage $\mathrm{CD} 44^{\mathrm{l}} \mathrm{CD} 62 \mathrm{~L}^{\mathrm{hi}}$ CD8 ${ }^{+}$of $C D 8^{+}$cells) (E), memory CD4 ${ }^{+} T$ cells (percentage CD44 ${ }^{\text {hi }}$ CD62L hicD4 $4^{+}$of $\mathrm{CD4} 4^{+}$cells) (F), and memory CD8 ${ }^{+} \mathrm{T}$ cells (percentage $\mathrm{CD} 44^{\text {hi }}{ }^{\mathrm{CD}} 62 \mathrm{~L}^{\text {hi }}{ }^{\mathrm{C}} \mathrm{CD} 8^{+}$of $\mathrm{CD} 8^{+}$cells) (C) were examined before the engraftment (Pre) and day 14 after the engraftment (Post). Black circles, $\mathrm{p} 110 \delta^{\mathrm{WT} / \mathrm{WT}}$; green squares, p110 $\delta^{\mathrm{D} 910 \mathrm{~A} / \mathrm{Dg} 10 \mathrm{~A}}-\mathrm{R}$; red triangles, p $110 \delta^{\text {D910A/D910A }-N R . ~ C o m p a r i s o n s ~ w e r e ~ b a s e d ~ o n ~ s e p a r a t e ~ m i x e d-~}$ effects models (log-transformed data); $P$ values were adjusted using Holm's procedure. (H) OVA-TCL1 cells were adoptively transferred into p $110 \delta^{W T / W T}$ and $p 110 \delta^{\text {D10A/D910A }}$ mice; OVA-specific CD $8^{+} T$ cells were examined weekly using fluorescent tagged OVA tetramer by flow cytometry. Bars represent mean \pm SD. (Group comparisons are based on mixed-effects models on log-transformed data; $P$ values were adjusted for multiple comparisons using Holm's procedure; 9 total time points examined.)

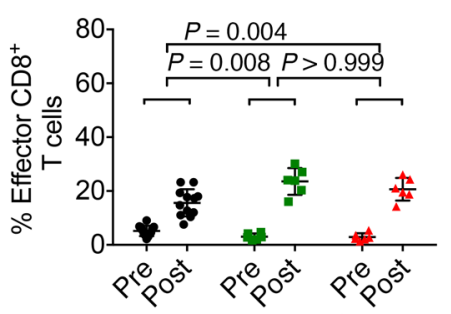

cocultured with splenic $\mathrm{p} 110 \delta^{\mathrm{WT} / \mathrm{WT}} \mathrm{CD} 4^{+} \mathrm{CD} 25^{-} \mathrm{T}$ cells in the presence of anti-CD3/anti-CD28 Dynabeads. The purities of $\mathrm{CD} 4{ }^{+} \mathrm{CD} 25^{-}$and $\mathrm{CD} 4{ }^{+} \mathrm{CD} 25^{+} \mathrm{T}$ cells were confirmed with intranuclear FoxP3 staining (Supplemental Figure $8 \mathrm{~A}$ ). In accordance with a previous report, $\mathrm{p} 110 \delta^{\mathrm{WT} / \mathrm{WT}}$ $\mathrm{CD} 4^{+} \mathrm{CD} 25^{+} \mathrm{T}$ cells suppressed $\mathrm{CD} 4^{+} \mathrm{CD} 25^{-} \mathrm{T}$ cell proliferation at a higher ratio, whereas $\mathrm{p} 110 \delta^{\mathrm{D} 910 \mathrm{~A} / \mathrm{D} 910 \mathrm{~A}} \mathrm{CD} 4^{+} \mathrm{CD} 25^{+}$ $\mathrm{T}$ cells failed to do so (Supplemental Figure 8B and ref. 60). To further investigate whether lack of Treg suppression and expansion are responsible for leukemia resistance, p110 $\delta^{\mathrm{D} 910 \mathrm{~A} / \mathrm{D} 910 \mathrm{~A}}$ mice were reconstituted with $\mathrm{p} 110 \delta^{\mathrm{WT} / \mathrm{WT}}$ Tregs followed by leukemia transfer. Day 27 after leukemia engraftment, $\mathrm{p} 110 \delta^{\mathrm{D} 910 \mathrm{~A} / \mathrm{D} 910 \mathrm{~A}}$ mice receiving $\mathrm{p} 110 \delta^{\mathrm{WT} / \mathrm{WT}}$ Tregs showed an abundant level of leukemia, whereas $\mathrm{p} 110 \delta^{\mathrm{D} 910 \mathrm{~A} / \mathrm{D} 910 \mathrm{~A}}$ mice left unengrafted or engrafted with p1108 $\delta^{\mathrm{D} 910 \mathrm{~A} / \mathrm{D} 910 \mathrm{~A}}$ Tregs had no evidence of disease (Supplemental Figure 8C).

p110 $\delta$ kinase inactivation in the microenvironment is also effective against myeloid leukemia. Acute myeloid leukemia (AML) is the most common adult leukemia of nonlymphocyte lineage and has a poor outcome with standard therapies (61). To examine whether the protective effect of p110 $\delta$ inactivation is observed across lineages to myeloid leukemia, an aggressive murine AML cell line of C57BL/6 background (Supplemental Figure 10), C1498-luciferase, was engrafted into $\mathrm{p} 110 \delta^{\mathrm{WT} / \mathrm{WT}}$ and $\mathrm{p} 110 \delta^{\mathrm{D} 910 \mathrm{~A} / \mathrm{D} 910 \mathrm{~A}}$ recipient mice. Disease burden was measured by whole-body luciferase activity using an In Vivo Imaging System (IVIS) (Supplemental Figure 9) and quantified for average fluorescence intensity. $\mathrm{p} 110 \delta^{\mathrm{D} 910 \mathrm{~A} / \mathrm{D} 910 \mathrm{~A}}$ mice showed less leukemia incidence $\left(\mathrm{p} 110 \delta^{\mathrm{WT} / \mathrm{WT}}\right.$, 7 of 10, vs. p110 $\delta^{\mathrm{DP10A} / \mathrm{D} 910 \mathrm{~A}}, 3$ of 10) and reduced overall disease burden compared with the wild-type controls (Figure 8).

\section{Discussion}

In this study, we identified, using genetic animal models, that the function of p1108, both in leukemia B cells and in the nonleukemic microenvironment, is critical for CLL pathogenesis. 
A
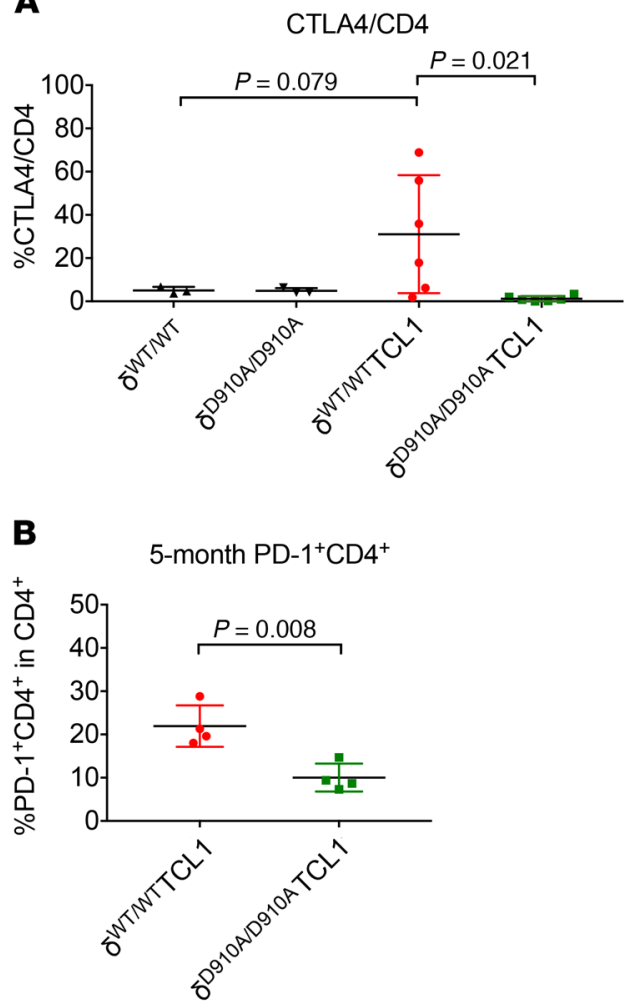

C

Blood

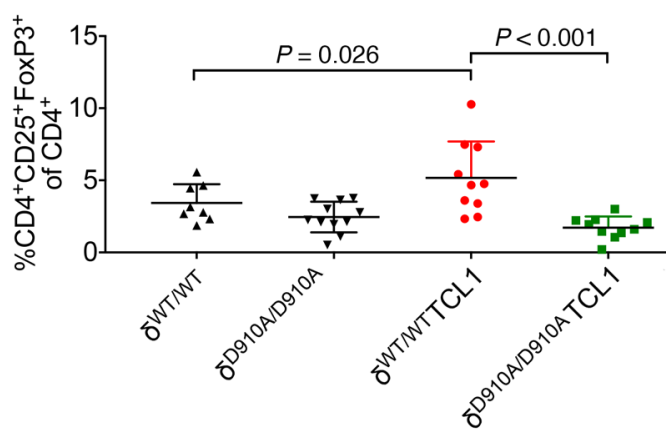

D

Tregs in spleen

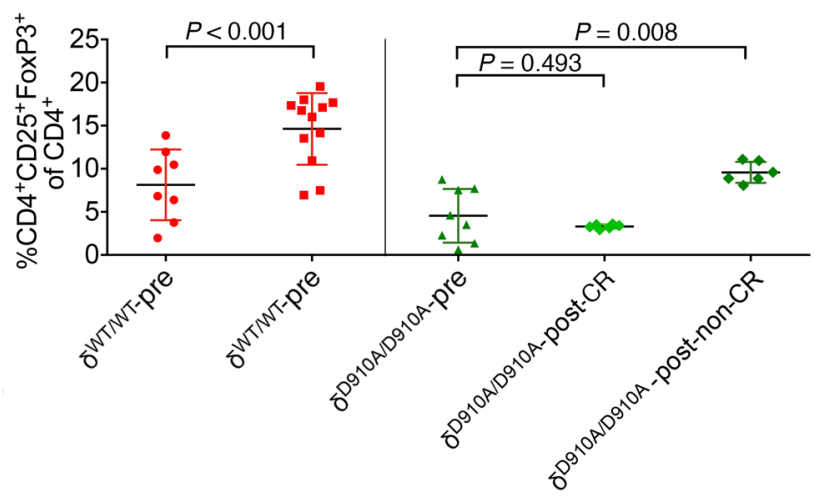

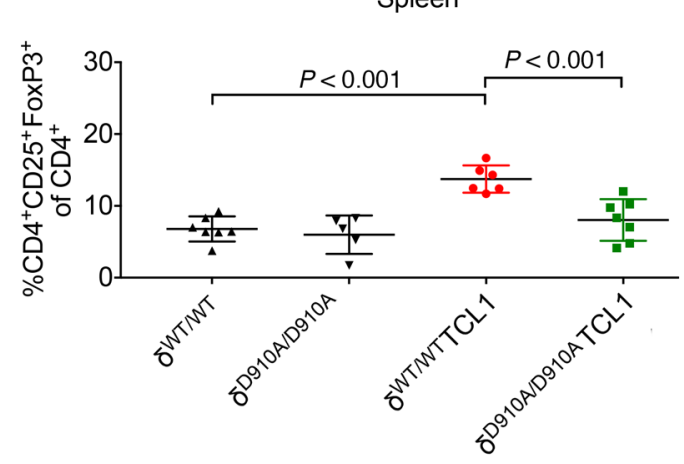

PD-1/CD4

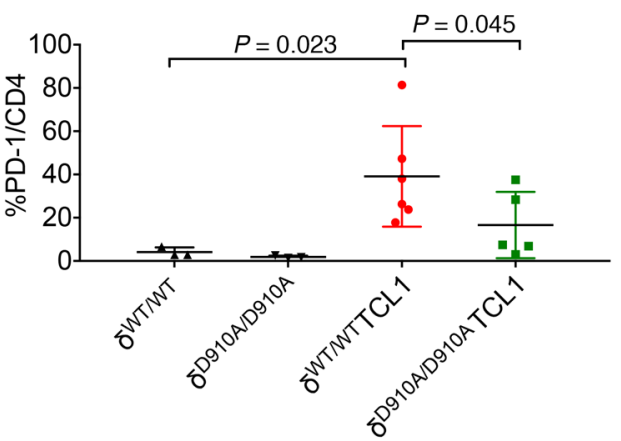

Spleen
Figure 7. p110 $\delta$ kinase inactivation reverses immune suppression in leukemia mice.

(A) Blood from 11-month-old $\mathrm{p} 110 \delta^{\mathrm{WT} / \mathrm{WT}}, \mathrm{p} 110 \delta^{\mathrm{D} 910 \mathrm{~A} / 0910 \mathrm{~A}}$, p110 $\delta^{\text {WT/WTTCL1 }}$, and p110 $\delta^{\text {D910A/D910ATCL1 mice }}$ was examined for immune checkpoint CTLA4 and PD-1 expression on $\mathrm{CD}^{+}{ }^{+}$cells by flow cytometry. (Separate ANOVA models were applied to each outcome. $P$ values within each outcome were adjusted for multiple comparisons using Holm's procedure.) (B) Blood from 5-month-old p110 $\delta^{\text {WT/WT }}$ TCL1 and $p 110 \delta^{\text {D910A/D910A }}$

TCL1 mice was examined for immune checkpoint PD-1 expression on $\mathrm{CD} 4^{+}$cells and leukemia burden by flow cytometry. (Group means were compared using 2-sample $t$ tests with unequal variances.)

(C) Relative Tregs (CD4+CD25+ $\mathrm{FoxP3}^{+}$of $\mathrm{CD}^{+}$cells) in blood and spleen of 9-month-old $\mathrm{p} 110 \delta^{\mathrm{WT} / \mathrm{WT}}, \mathrm{p} 110 \delta^{\mathrm{D} 910 \mathrm{~A} / \mathrm{Dg} 10 \mathrm{~A}}$, p110 $\delta^{\mathrm{WT} / \mathrm{WT}} \mathrm{TCL} 1$, and p110 $\delta^{\text {D910A/D910A TCL1 mice were }}$ examined by flow cytometry. (Separate ANOVA models were applied to each outcome. $P$ values within each outcome were adjusted for multiple comparisons using Holm's procedure.) (D) Frequency of Tregs (CD4 ${ }^{+} \mathrm{CD} 25^{+} \mathrm{FoxP3}^{+}$of $\mathrm{CD} 4^{+}$ cells) in spleen was examined in $\mathrm{p} 110 \delta^{\mathrm{WT} / \mathrm{WT}}$ and $\mathrm{p} 110 \delta^{\mathrm{Dg} 10 \mathrm{~A} / \mathrm{Dg} 10 \mathrm{~A}}$ mice on day 14 after adoptive transfer with $2 \times 10^{7} \mathrm{E} \mu$-TCL1 secondary leukemia cells. (Differences were estimated using ANOVA.) Bars represent mean \pm SD.
Global inactivation of $\mathrm{p} 110 \delta$ in the E$\mu$-TCL1 murine CLL model blocks leukemia progression in blood and major lymphoid organs. B cells from $\mathrm{p} 110 \delta^{\mathrm{D} 910 \mathrm{~A} / \mathrm{D} 910 \mathrm{~A}} \mathrm{TCL} 1$ mice still exhibit partially impaired BCR signaling and migratory function. Inactivation of p110 in the nonleukemic microenvironment also protects against leukemia through a $\mathrm{T}$ cell-dependent mechanism. Despite dampened antigen-specific $\mathrm{CD}^{+} \mathrm{T}$ cell responses, $\mathrm{p} 110 \delta$-inactivated $\mathrm{T}$ cells remain cytotoxic to leukemia cells. It is possible that $\mathrm{p} 110 \delta$ 


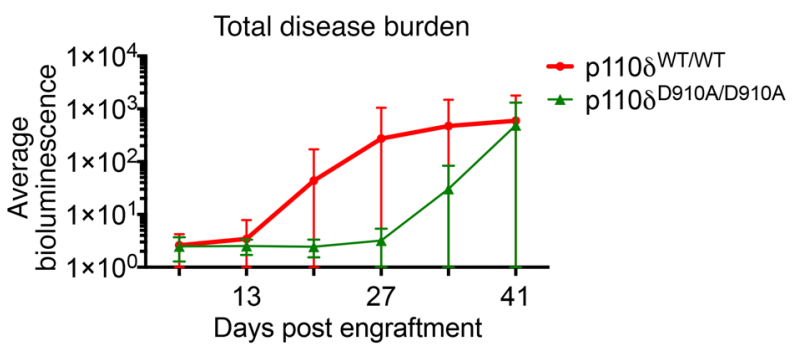

inactivation impairs Treg expansion followed by enhanced host antitumorimmunity. Reconstituted $110 \delta^{\mathrm{D} 910 \mathrm{~A} / \mathrm{D} 910 \mathrm{~A}}$ micewithp $110 \delta^{\mathrm{WT} / \mathrm{WT}}$ Tregs reversed such disease resistance. Nonetheless, p110 $\delta$ inactivation introduces side effects such as colitis, suggesting autoimmunity. These murine studies further confirmed that the colitis is an on-target side effect of idelalisib treatment in patients with CLL and non-Hodgkin's lymphoma (NHL). Finally, we demonstrate that the antitumor benefits of $\mathrm{p} 110 \delta$ inactivation are not lineage specific, as it also impacted engraftment and dissemination of murine AML. Taken together, our study supports that $\mathrm{p} 110 \delta$ inhibition presents an attractive therapeutic option in multiple cancer types, and that p110 $\delta$ inhibitors may be used for immunomodulation in disseminated models of cancer.

The E $\mu$-TCL1 murine CLL model is by far the most validated and characterized spontaneous in vivo model of human CLL (46, $49,50,52,53)$. Extensive studies on BCR signaling and microenvironment regulation have been performed using this model. Since the development of inhibitors of kinases associated with the BCR signalosome, many genetic models emerged to investigate the mechanism of these agents $(57,62-65)$. Interestingly, multiple kinases belonging to the BCR signalosome have dual functions in both the leukemic and the nonleukemic cell compartments. For example, PKC $\beta$ is required by both CLL cells and bone marrow cells to maintain leukemogenesis $(62,63)$. Additionally, LYN ${ }^{-/} / \mathrm{TCL} 1$ mice have delayed leukemia onset, and $\mathrm{LYN}^{-/-}$mice are resistant to leukemia engraftment (64). Despite the FDA approval of idelalisib in relapsed and refractory CLL, the exact mechanism of p110 $\delta$ remains elusive. Many in vitro characterizations highlight the importance of p110 $\delta$ in BCR signaling (66-69). However, the role of p110 $\delta$ outside of leukemic cells remains unclear. Here, we provide what is to our knowledge the first direct evidence that $\mathrm{p} 110 \delta$ activity is critical for both the leukemic and nonleukemic compartments. Compared with

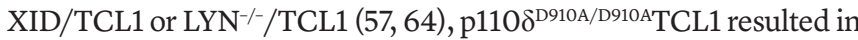
much more dramatic disease suppression (Figure 2A). In addition, we show that $\mathrm{p} 110 \delta$ is required for $\mathrm{T}$ cell immune tolerance. $\mathrm{p} 110 \delta$ inactivation suppresses Treg expansion (Figure 7, C and D), which correlates with disease progression in this model. Our data validate that $110 \delta$ blockade in CLL is efficacious and provide evidence that p110 $\delta$ blockade can be immunomodulatory.

$\mathrm{p} 110 \delta^{\mathrm{D} 910 \mathrm{~A} / \mathrm{D} 910 \mathrm{~A}}$ mice have been reported to have compromised BCR signaling (18), and our data show that despite the TCL1 transgene, B cells from $110 \delta^{\mathrm{D} 910 \mathrm{~A} / \mathrm{D} 910 \mathrm{~A}} \mathrm{TCL} 1$ mice still exhibit partially compromised BCR signaling and impaired migration toward CXCL13 (Figure 1 and Supplemental Figure 1). However, we cannot exclude the effect of $\mathrm{p} 110 \delta$ blockade in the microenvironment in the global inactivation model, since $\mathrm{p} 110 \delta^{\mathrm{D} 910 \mathrm{~A} / \mathrm{D} 910 \mathrm{~A}}$ mice resist leukemia engraftment (Figure 4). To further confirm the precise
Figure 8. p110 $\delta$ kinase inactivation in the microenvironment is also effective against myeloid leukemia. $p 110 \delta^{\mathrm{WT} / \mathrm{WT}}(n=10)$ and $\mathrm{p} 110 \delta^{\mathrm{Dg10A} / \mathrm{Dg} 10 \mathrm{~A}}$ $(n=10)$ mice were engrafted with C1498-luciferse cells through tail vein injection; the leukemia burden was examined by the amount of bioluminescence with an IVIS imager. Overall tumor kinetics is quantified by average bioluminescence of every mouse in each group. Data represent mean \pm SD.

role of $\mathrm{p} 110 \delta$ in the B cell compartment, it would be of interest to generate B cell-specific p110 $\delta$ inactivation. In addition, given that $\mathrm{p} 110 \delta^{\mathrm{D} 910 \mathrm{~A} / \mathrm{D} 910 \mathrm{~A}} \mathrm{TCL} 1$ mice have sustained $\mathrm{p} 110 \delta$ inhibition prior to disease development and TCL1 acts in the exact pathway downstream of PI3K signaling, it would be of interest to create an inducible model where $\mathrm{p} 110 \delta$ kinase inactivation could be turned on upon disease development. Additional CLL murine models should also be tested to validate these findings.

The E $\mu$-TCL1 transgenic mouse is also valuable for investigating CLL immune dysfunction. Upon disease development, E $\mu$-TCL1 mice or syngeneic mice with adoptively transferred leukemia cells develop $\mathrm{T}$ cell defects and profound immunodeficiency closely resembling what is observed in CLL patients $(47,49,70)$. However, few therapeutic agents have been developed that target the leukemia microenvironment. Emerging studies have revealed the critical roles T cells play in the pathogenesis of CLL. For example, CLL cells are known to induce the generation and/or accumulation of memory CD $4^{+} \mathrm{T}$ cells. Despite being an important component of the immune system, $\mathrm{T}$ cells can be exploited by CLL cells for their own survival. Owing to the weak antigen stimulation, CLL can induce naive T cells to become central memory $\mathrm{T}$ cells. These central memory $\mathrm{T}$ cells can then migrate toward the lymphoid niches because of their high CXCR5 expression and provide costimulatory signaling to CLL cells through CD4OL and cytokine production (71). Effector memory T cells can also contribute to CLL progression through IL-4 and IFN- $\gamma$ production. Given that $\mathrm{p} 110 \delta$ is abundantly expressed in T lymphocytes and plays critical roles in T cell biology, we suspect that inactivation of p110 in T cells would compromise their ability to support CLL. In accordance with our hypothesis, we found that $\mathrm{p} 110 \delta^{\mathrm{D} 910 \mathrm{~A} / \mathrm{D} 910 \mathrm{~A}}$ mice resisted leukemia development (Figure 4) and generated significantly fewer memory CD $4^{+} \mathrm{T}$ cells (Figure $6 \mathrm{~F}$ ).

From our observation, it first seemed that both $\mathrm{CD}^{+} \mathrm{T}$ cells and $\mathrm{CD}^{+} \mathrm{T}$ cells are critical for the leukemia resistance in p110 $\delta^{\mathrm{D} 910 \mathrm{~A} / \mathrm{D} 910 \mathrm{~A}}$ mice (Figure 5D). However, depleting $\mathrm{CD}^{+} \mathrm{T}$ cells in E $\mu$-TCL1 mice also leads to higher leukemia burden (72). All of this is contradictory to what was observed in mice bearing solid tumors. Depleting CD4 ${ }^{+} \mathrm{T}$ cells in $4 \mathrm{~T} 1$ tumor-bearing p110 $\delta^{\mathrm{D} 910 \mathrm{~A} / \mathrm{D} 910 \mathrm{~A}}$ mice did not accelerate disease (31). Depletion of $\mathrm{CD}^{+} \mathrm{T}$ cells in wild-type C3B6F1 mice inoculated with Ag104Ld tumor resulted in complete tumor rejection (73). We hypothesize that $\mathrm{CD}^{+} \mathrm{T}$ cells are critical as $\mathrm{T}$ helper cells at the initial antigen recognition/presentation stage. In the case of solid tumor, $\mathrm{CD}^{+}$ Tregs accumulate in a confined location as disease progresses, effectively suppressing antitumor $\mathrm{CD}^{+} \mathrm{T}$ cells. Depleting $\mathrm{CD} 4^{+}$ $\mathrm{T}$ cells under this circumstance removes Tregs from the suppression. In $4 \mathrm{~T} 1$ tumor-bearing $\mathrm{p} 110 \delta^{\mathrm{D} 910 \mathrm{~A} / \mathrm{D} 910 \mathrm{~A}}$ mice, in which 
Treg expansion was already impaired (31), CD $4^{+} \mathrm{T}$ cell depletion would not affect disease course. In disseminated leukemia, it is possible that $\mathrm{CD} 8^{+} \mathrm{T}$ cells rely on $\mathrm{CD} 4^{+} \mathrm{T}$ cells' help. Therefore, leukemia-bearing mice depleted of $\mathrm{CD} 4^{+} \mathrm{T}$ cells would suffer from the loss of $\mathrm{T}$ helper cells rather than benefit from the removal of Tregs. This hypothesis is also supported by our observation that transferring either $\mathrm{p} 110 \delta^{\mathrm{WT} / \mathrm{WT}}$ or $\mathrm{p} 110 \delta^{\mathrm{D} 910 \mathrm{~A} / \mathrm{D} 910 \mathrm{~A}}$ $\mathrm{CD}^{+}$or $\mathrm{CD}^{+}{ }^{+} \mathrm{T}$ cells with E $\mu$-TCL1 leukemia into $\mathrm{RAG}^{-/-}$mice slows down disease compared with transferring leukemia alone (Supplemental Figure 4A).

Owing to the direct antitumor cytotoxicity of $\mathrm{CD}^{+} \mathrm{T}$ cells, it is not surprising to see that depleting $\mathrm{CD}^{+} \mathrm{T}$ cells in $\mathrm{p} 110 \delta^{\mathrm{D} 910 \mathrm{~A} / \mathrm{D} 910 \mathrm{~A}}$ mice bearing either $\mathrm{E} \mu-\mathrm{TCL} 1$ leukemia or $4 \mathrm{~T} 1$ solid tumor led to higher disease burden (Figure 5, C and D, and ref. 31). Moreover, depletion of $\mathrm{CD}^{+} \mathrm{T}$ cells rather than $\mathrm{CD} 4^{+} \mathrm{T}$ cells in $\mathrm{p} 110 \delta^{\mathrm{D} 910 \mathrm{~A} / \mathrm{D} 910 \mathrm{~A}}$ mice reversed leukemia resistance in the bone marrow compartment (Figure 5D). In contrast, replenishing $\mathrm{RAG}^{-1-}$ mice with either $\mathrm{p} 110 \delta^{\mathrm{WT} / \mathrm{WT}}$ or $\mathrm{p} 110 \delta^{\mathrm{D} 910 \mathrm{~A} / \mathrm{D} 910 \mathrm{~A}} \mathrm{CD} 8^{+} \mathrm{T}$ cells leads to the least amount of disease in comparison with their samegenotype counterparts (Supplemental Figure 4, A and C). All of this further highlights the importance of $\mathrm{CD}^{+} \mathrm{T}$ cells in the antitumor immunity of $\mathrm{p} 110 \delta^{\mathrm{D} 910 \mathrm{~A} / \mathrm{D} 910 \mathrm{~A}}$ mice.

Moreover, it was also reported that $\mathrm{p} 110 \delta^{\mathrm{D} 910 \mathrm{~A} / \mathrm{D} 910 \mathrm{~A}}$ mice generated a comparable number of OVA-specific $\mathrm{CD}^{+} \mathrm{T}$ cells to that seen in $\mathrm{p} 110 \delta^{\mathrm{WT} / \mathrm{WT}}$ mice upon subcutaneous inoculation of OVA-expressing Lewis lung carcinoma cells (LLC-OVA) (31). However, we found that upon adoptive transfer of OVA-TCL1 cells, $\mathrm{p} 110 \delta^{\mathrm{D} 910 \mathrm{~A} / \mathrm{D} 910 \mathrm{~A}}$ mice developed approximately half the number of OVA-specific CD $8^{+} \mathrm{T}$ cells compared with $\mathrm{p} 110 \delta^{\mathrm{WT} / \mathrm{WT}}$ mice (Figure $6 \mathrm{H}$ and Supplemental Figure 6). This may contradict our finding that $\mathrm{CD}^{+} \mathrm{T}$ cell-replenished $\mathrm{RAG}^{-/-}$mice had the least amount of disease. The discrepancy of these data may be due to the disseminated nature of leukemia inducing different host antitumor immunity (74) and tolerance. Localized tumors are susceptible to the immune surveillance enforced by tumor-infiltrating lymphocytes; however, the immunosuppressive microenvironment may prevent local activation or effector function. In contrast, disseminated tumors like leukemia are more vulnerable to immune surveillance once in the lymphatic/blood circulation, which may place less pressure for immune activation.

Although inactivation of $\mathrm{p} 110 \delta$ in mice partially dampens $\mathrm{CD} 4^{+}$ and $\mathrm{CD}^{+} \mathrm{T}$ cell function, these mice remain resistant to Leishmania major infection and a broad range of solid tumor engraftments $(31,75)$. This is due to severely suppressed Treg expansion and defects in suppressive activity. In agreement with previous reports, we also found that Treg expansion was impaired in $\mathrm{p} 110 \delta^{\mathrm{D} 910 \mathrm{~A} / \mathrm{D} 910 \mathrm{~A}} \mathrm{TCL} 1 \mathrm{mice}$ and p110 $\delta^{\mathrm{D} 910 \mathrm{~A} / \mathrm{D} 910 \mathrm{~A}}$ mice into which E $\mu$-TCL1 leukemia cells were adoptively transferred (Figure 7D). Replenishing $\mathrm{p} 110 \delta^{\mathrm{D} 910 \mathrm{~A} / \mathrm{D} 910 \mathrm{~A}}$ mice with $\mathrm{p} 110 \delta^{\mathrm{WT} / \mathrm{WT}}$ Tregs reversed the leukemia resistance (Supplemental Figure 8C), providing direct evidence that the lack of Treg expansion protects $\mathrm{p} 110 \delta^{\mathrm{D} 910 \mathrm{~A} / \mathrm{D} 910 \mathrm{~A}}$ mice from developing leukemia. Treg expansion is found in CLL and AML patients and associated with progressive disease. Our finding suggests that p110 $\delta$ blockade could be used as an immune-modulatory agent for these diseases.

One major consequence of $110 \delta$ inhibition seen in the clinic is autoimmunity (16). Despite low leukemic incidence, $\mathrm{p} 110 \delta^{\mathrm{D} 910 \mathrm{~A} / \mathrm{D} 910 \mathrm{~A}} \mathrm{TCL} 1 \mathrm{mice}$ had shortened overall survival due to autoimmune colitis (Figure 3). It has been previously described that $\mathrm{p} 110 \delta^{\mathrm{D} 910 \mathrm{~A} / \mathrm{D} 910 \mathrm{~A}}$ mice spontaneously develop colitis due to an exaggerated mucosal and systemic Th1/Th17 cytokine profile and altered macrophage function (60). We observed neutrophilic colitis accompanied by rectal prolapse in both $\mathrm{p} 110 \delta^{\mathrm{D} 910 \mathrm{~A} / \mathrm{D} 910 \mathrm{~A}}$ and p110 $\delta^{\mathrm{D} 910 \mathrm{~A} / \mathrm{D} 910 \mathrm{~T}} \mathrm{TCL} 1$ mice. Both the Treg suppression and colitis symptoms are observed in CLL patients with idelalisib treatment and associated with liver toxicity (16). Our genetic model, therefore, provides strong and precise evidence that the gastrointestinal consequence of idelalisib is an on-target side effect of p110 $\delta$ blockade.

This autoimmune phenotype in the mouse model, however, presents a significant confounding factor in the disease tracking of p110 $\delta^{\mathrm{D} 910 \mathrm{~A} / \mathrm{D} 910 \mathrm{~T}} \mathrm{TCL} 1$. It remains unknown how the disease might develop in $\mathrm{p} 110 \delta^{\mathrm{D} 910 \mathrm{~A} / \mathrm{D} 910 \mathrm{~T}} \mathrm{TCL} 1 \mathrm{mice}$ if they are free of autoimmune complication. Compelling evidence suggests that the microbiota helps to shape the immune system as a whole (76). Germ-free (GF) mice that lack intestinal microbiota are reported to have defective immune response $(77,78)$. Dysbiosis, which is characterized by a less diverse and less stable microbiota, can lead to systemic activation of Th17 cells and effector T cells $(79,80)$. The colitis observed in $\mathrm{p} 110 \delta^{\mathrm{D} 910 \mathrm{~A} / \mathrm{D} 910 \mathrm{~A}}$ mice is believed to be caused by the presence of enteric microbiota dysbiosis (81). $\mathrm{p} 110 \delta^{\mathrm{D} 910 \mathrm{~A} / \mathrm{D} 910 \mathrm{~A}}$ mice that were housed GF did not develop histologic colitis up to 30 weeks of age. However, 7 days upon transfer to traditional housing, $\mathrm{p} 110 \delta^{\mathrm{D} 910 \mathrm{~A} / \mathrm{D} 910 \mathrm{~A}}$ mice showed significant colonic inflammation and an increased colitis score (81). Given the increasing evidence suggesting the association between microbiota and antitumor immunity (80), it is reasonable to hypothesize that the enhanced antitumor immunity in $\mathrm{p} 110 \delta^{\mathrm{D} 910 \mathrm{~A} / \mathrm{D} 910 \mathrm{~A}}$ mice may be associated with colitis symptoms. It is fascinating for us to observe that compared with $\mathrm{p} 110 \delta^{\mathrm{WT} / \mathrm{WT}}$ or $\mathrm{p} 110 \delta^{\mathrm{D} 910 \mathrm{~A} / \mathrm{D} 910 \mathrm{~A}}-\mathrm{non}-\mathrm{CR}$ mice, $\mathrm{p} 110 \delta^{\mathrm{D} 910 \mathrm{~A} / \mathrm{D} 910 \mathrm{~A}}-\mathrm{CR}$ mice have a higher plasma IL-17 level and a lower IL-10 level (data not shown). They are also the only group that had detectable plasma IL-12p70 (data not shown). These cytokine profiles are consistent with what was observed in $\mathrm{p} 110 \delta^{\mathrm{D} 910 \mathrm{~A} / \mathrm{D} 910 \mathrm{~A}}$ mice that developed microbiotadependent colitis due to the defects in macrophages (81). Because the experiment was short-term, we did not observe any apparent colitis. However, it would be of interest to examine the antitumor immunity of $\mathrm{p} 110 \delta^{\mathrm{D} 910 \mathrm{~A} / \mathrm{D} 910 \mathrm{~A}}$ mice in GF condition to test whether the leukemia resistance associates with microbiota-dependent colitis. On a separate note, it seems interesting that $\mathrm{p} 110 \delta^{\mathrm{D} 910 \mathrm{~A} / \mathrm{D} 910 \mathrm{~A}}$ TCL1 mice gain survival advantages over $110 \delta^{\mathrm{D} 910 \mathrm{~A} / \mathrm{D} 910 \mathrm{~A}}$ mice. While p110 $\delta^{\text {D910A/D910A } T C L 1 ~ m i c e ~ a p p e a r ~ t o ~ h a v e ~ a ~ s i m i l a r ~ l e v e l ~ o f ~ c o l i t i s ~}$ to $\mathrm{p} 110 \delta^{\mathrm{D} 910 \mathrm{~A} / \mathrm{D} 910 \mathrm{~A}}$ mice at the time of assessment, it remains to be explored whether the presence of TCL1 transgene delays the onset of colitis symptoms.

Given that p110 is also abundantly expressed in myeloid cells $(82,83)$, it is possible that inactivation of $110 \delta$ affected their crosstalk with leukemia. It has been shown that myeloid-derived suppressor cells (MDSCs) from solid tumor-bearing $\mathrm{p} 110 \delta^{\mathrm{D} 910 \mathrm{~A} / \mathrm{D} 910 \mathrm{~A}}$ mice are less suppressive than their wild-type counterparts (31). However, it was not clear whether it was an intrinsic difference in these myeloid cells or an indirect result of less disease burden. The same study also reported that $\mathrm{RAG}^{-/-} \mathrm{p} 110 \delta^{\mathrm{D} 910 \mathrm{~A} / \mathrm{D} 910 \mathrm{~A}}$ mice bearing $4 \mathrm{~T} 1$ solid tumor exhibited similar primary tumor burden but fewer metastatic lesions, suggesting that inactivation of $\mathrm{p} 110 \delta$ in non-B/T cell lineage is not sufficient to delay tumor progression (31). It would be interesting 
for future studies to determine whether inactivation of $\mathrm{p} 110 \delta$ in the myeloid compartment contributes to leukemia resistance.

In summary, we believe that our study provides the first genetic evidence confirming the functional role of $\mathrm{p} 110 \delta$ in CLL initiation and progression and $\mathrm{T}$ cell tumor immune tolerance. Additionally, this finding is reproducible in another distinct disseminated model of AML. These findings improve our understanding of the mechanism of action of $\mathrm{p} 110 \delta$ small-molecule inhibitors. Furthermore, these findings suggest the immunoregulatory potential of $\mathrm{p} 110 \delta$ inhibitors and highlight the importance of prophylactic care for on-target side effects associated with p110 $\delta$ blockade.

\section{Methods}

Supplemental Methods are available online with this article; https:// doi.org/10.1172/JCI99386DS1.

Cells and reagents. The C1498-luciferase cell line was a gift from Bruce R. Blazar (University of Minnesota, Minneapolis, Minnesota, USA). Antibodies against cell surface markers or intracellular proteins were from: BD Biosciences: CD45 (30-F11), CD19 (1D3), CD5 (53-7.3), CD3 (134-2C11), CD4 (RM4-5), CD8a (53-6.7), CD25 (PC61), CTLA4 (UC10-4B9), PD-1 (J43), PD-L1 (MIH5), CD44 (IM7), CD62L (MEL-14); eBioscience: FoxP3 (FJK-16s). Antibodies for depletion of CD4 (GK1.5) or CD8 (53-6.72) cells were from Bio X Cell. Isotype control antibodies were LTF-2 and 2A3 from Bio X Cell. CountBright beads were obtained from Invitrogen and used per the manufacturer's instructions.

Mice. All animal experiments were performed under a protocol approved by the Ohio State University Institutional Laboratory Animal Care and Use Committee. E $\mu$-TCL1 transgenic mice and PI3K p110 $\delta$ mice were provided by Carlo M. Croce (The Ohio State University, Columbus, Ohio, USA) and Bart Vanhaesebroeck (University College London, London, UK), respectively. E $\mu$-TCL1-transgenic mice on a C57BL/6J (B6) background have been previously described (45). This mouse strain has been extensively backcrossed with the B6 mouse to obtain a E $\mu$-TCL1-expressing mouse on a pure B6 background. PI3K p110 $\delta^{\mathrm{D} 910 \mathrm{~A}}$ mice have been previously described (18) and were backcrossed on C57BL/6J for more than 12 generations. To generate $\mathrm{p} 110 \delta^{\mathrm{D} 910 \mathrm{~A} / \mathrm{D} 910 \mathrm{~A}} \mathrm{TCL} 1$ mice, homozygous $\mathrm{B} 6 / \mathrm{E} \mu-\mathrm{TCL} 1$ mice were crossed with homozygous $\mathrm{p} 110 \delta^{\mathrm{D} 910 \mathrm{~A}}$ mice to generate $\mathrm{p} 110 \delta^{\mathrm{WT} / \mathrm{D} 910 \mathrm{~A}}$ TCL1 mice. p110 $\delta^{\mathrm{WT} / \mathrm{D} 910 \mathrm{~T}} \mathrm{TCL} 1$ mice were further crossed with each other to generate $\mathrm{p} 110 \delta^{\mathrm{WT} / \mathrm{WT} T C L 1}$ mice and $\mathrm{p} 110 \delta^{\mathrm{D} 910 \mathrm{~A} / \mathrm{D} 910 \mathrm{ATC}} \mathrm{TC} 1 \mathrm{mice}$. For survival studies, mice were euthanized when they reached earlyremoval criteria by animal protocol, including lethargy, difficulty walking due to spleen size, or loss of $20 \%$ body weight. Animals were evaluated daily, with formal measurements of weight weekly during engraftment studies and biweekly or monthly for long-term studies. For experiments characterizing disease compartments, mice were euthanized at stated ages, and blood from heart puncture, bone marrow, and spleen samples were collected for further analysis.

Adoptive transfer studies. For E $\mu$-TCL1 engraftment studies, leukemic spleen lymphocytes were obtained from B6/E $\mu$-TCL1 mice with high white blood cell counts and splenomegaly. Spleens were manually disrupted, and spleen lymphocyte single cells were obtained by homogenization of the tissue and filtering of cells through a 100- $\mu$ m nylon cell strainer (BD Falcon, Heidelberg, Germany). Red cells were lysed with RBC lysis buffer (eBioscience). Flow cytometry was used to confirm that lymphocytes were leukemia, and then spleen lymphocytes were resuspended in sterile PBS and injected through a lateral tail vein. For $\mathrm{p} 110 \delta^{\mathrm{D} 910 \mathrm{~A} / \mathrm{D} 910 \mathrm{~A}}$ and B6 engraftments, $5 \times 10^{6}$ to $2 \times 10^{7}$ cells were injected into each mouse, with equal amounts used for each individual experiment. Submandibular bleeding was used to obtain blood for smears and flow cytometry to evaluate disease progression. For C1498-luciferase cell adoptive transfer, leukemia burden was determined via luciferase activity measured by an In Vivo Imaging System (IVIS) imager (PerkinElmer).

In vivo $C D 4^{+}$and $C D 8^{+} T$ cell depletion study. In vivo antibody depletion studies were initiated 10 days after leukemia adoptive transfer; antibodies were administered through i.p. injection of $0.5 \mathrm{mg}$ of antibodies to CD4 or CD8 (or antibody isotype controls) every 3 days, for the duration of the study.

Flow cytometry. Peripheral blood leukemia involvement was performed by staining of fresh whole blood with anti-mouse CD45-APC, anti-mouse CD5-FITC, and anti-mouse CD19-PE (all from BD Biosciences). Absolute counts of CLL cells were determined through gating on live $\mathrm{CD} 45^{+} \mathrm{CD}^{+} \mathrm{CD} 19^{+}$cells and counting beads (CountBright absolute counting beads; Invitrogen) following the manufacturer's recommendations. Flow cytometry was performed on a Beckman Coulter FC-500 flow cytometer or a BD LSRFortessa, and Kaluza software was used for data analysis.

Isolation of murine cells. Purification of murine B cells was performed by negative selection using an EasySep Mouse B Cell Isolation Kit according to the manufacturer's instruction.

$B C R$ cross-linking experiments and immunoblot analysis. Murine spleen white blood cells were either left unstimulated or stimulated with $\mathrm{F}\left(\mathrm{ab}^{\prime}\right)_{2}$ goat anti-mouse IgM (Jackson ImmunoResearch Laboratories; Dianova). Whole cell lysates were prepared as previously described by our group (84). Equivalent amounts of protein were loaded onto polyacrylamide gels and transferred onto nitrocellulose membranes. Following antibody incubations, proteins were detected with chemiluminescent substrate (SuperSignal; Pierce). Phospho-AKT (Ser473) (D9W9U; 12694), total AKT (polyclonal; 9272), phospho-p44/42 MAPK (ERK1/2) (Thr202/Tyr204) (polyclonal; 9101), total ERK1/2 (polyclonal; 9102), phospho-IкB $\alpha$ (Ser32/36) (5A5; 9246), and total ІкB $\alpha$ (112B2; 9247) antibodies were obtained from Cell Signaling Technology.

Histopathology. Spleen, liver, heart, lungs, kidneys, gastrointestinal tract, sternal bone marrow, thymus, and mesenteric lymph nodes were collected following natural death or euthanasia due to fulfillment of early-removal criteria. Tissues were examined grossly and microscopically. Tissues were fixed in 10\% neutral-buffered formalin, paraffin-embedded, and sectioned at $3 \mu \mathrm{m}$ onto glass slides with $\mathrm{H} \& \mathrm{E}$ staining by routine methodology. Sternums (for bone marrow) were decalcified in $10 \%$ formic acid solution for 24 hours immediately prior to paraffin embedding.

Statistics. For Western blot data (Figure 1B, Supplemental Figure 1B, and Supplemental Figure 8C), ANOVA methods were used to compare group means; outcome data were log-transformed to stabilize variances. Mixed-effects models were used for Figure 2C, Figure 4A, Figure 5, A-C, Figure 6, A-G, and Supplemental Figure 1C, to account for correlations among observations from the same subject; as with the Western blot data, outcomes were first log-transformed. Estimated differences with 95\% confidence intervals were obtained from the models, and $P$ values were adjusted for multiple comparisons using Holm's procedure. For experiments described in Figure 4C, Figure 5D, Figure 7, A-D, and Supplemental Figure 8B, 2-sided 2-sample $t$ tests using unequal variances or ANOVA methods were used to compare group means. The nonparametric Wilcoxon rank sum test was used to compare groups for 
Supplemental Figure 4, A and B. $P$ values were adjusted for multiple comparisons using Holm's procedure.

For the mouse survival models described in Figure 2B, Figure 3A, Figure 4B, and Supplemental Figure 2, B and C, estimated times to leukemia development or overall survival (OS) were obtained using the Kaplan-Meier method, and the log-rank test evaluated differences between curves. Time to leukemia was defined as the date of engraftment to the date of flow cytometry showing CD5/CD19 in more than $10 \%$ of lymphocytes. OS was defined as the time from either birth or development of leukemia (noted in each individual experiment) until death. Spleen weight (Figure 2C) was compared between groups using the Wilcoxon rank sum test. All analyses were performed using SAS/STAT software (SAS version 9.4 for Windows, SAS Institute Inc.). $P$ values less than 0.05 were considered significant.

Study approval. All animal studies were approved by the Institutional Animal Care and Use Committees at The Ohio State University (Columbus, Ohio, USA).

\section{Author contributions}

$\mathrm{SD}$ contributed to the design and performance of the experiments, data analysis, and writing of the manuscript. $\mathrm{BKH}$ processed pathology samples and acquired and analyzed pathology data. EYH performed the flow sort and acquired and analyzed data. JTG performed the tritiated thymidine incorporation assay and acquired and analyzed data. AML performed the statistical analysis and interpret- ed data. MT and RLW contributed to mouse colony maintenance and blood and tissue harvesting. ML, NM, JRB critically reviewed the manuscript and helped with data interpretation. AJJ and JCB designed the study, secured funding, directed the research, analyzed data, and provided overall guidance of the project and manuscript.

\section{Acknowledgments}

The authors gratefully acknowledge Carlo Croce for providing the E $\mu$-TCL1 mice, Bart Vanhaesebroeck for providing the PI3K p110 $\delta^{\mathrm{D} 910 \mathrm{~A} / \mathrm{D} 910 \mathrm{~A}}$ mice, and Bruce R. Blazar for providing the C1498-luciferase cell line. This work was supported by grants from the NIH (R01CA159296, R01CA213442, R35CA197734, and F30CA225070-01A1), the Leukemia \& Lymphoma Society, the American Society of Hematology, and the Pelotonia Fellowship Program, as well as Michael and Judy Thomas, the D. Warren Brown Foundation, and the Four Winds Foundation.

Address correspondence to: John C. Byrd, The Ohio State University Comprehensive Cancer Center, 455 Wiseman Hall, 410 West 12th Avenue, Columbus, Ohio 43210, USA. Phone: 614.293.8330; Email: john.byrd@osumc.edu. Or to: Amy J. Johnson, Janssen Research and Development, Oncology Translational Research, 1400 McKean Road, Spring House, Pennsylvania 19477, USA. Phone: 215.986.1650; Email: ajohn118@its.jnj.com.
1. Burger JA. Nurture versus nature: the microenvironment in chronic lymphocytic leukemia. Hematology Am Soc Hematol Educ Program. 2011;2011:96-103.

2. Purroy N, Wu CJ. Coevolution of leukemia and host immune cells in chronic lymphocytic leukemia. Cold Spring Harb Perspect Med. 2017;7(4):a026740.

3. Kipps TJ, et al. Chronic lymphocytic leukaemia. Nat Rev Dis Primers. 2017;3:16096.

4. Burger JA, et al. High-level expression of the T-cell chemokines CCL3 and CCL 4 by chronic lymphocytic leukemia B cells in nurselike cell cocultures and after BCR stimulation. Blood. 2009;113(13):3050-3058.

5. Ghia P, et al. Chronic lymphocytic leukemia B cells are endowed with the capacity to attract $\mathrm{CD}^{+}, \mathrm{CD}^{+} \mathrm{OL}^{+} \mathrm{T}$ cells by producing CCL22. Eur J Immunol. 2002;32(5):1403-1413.

6. Zucchetto A, et al. Monocytes/macrophages but not $\mathrm{T}$ lymphocytes are the major targets of the CCL3/CCL4 chemokines produced by CD38(+) CD49d(+) chronic lymphocytic leukaemia cells. Br J Haematol. 2010;150(1):111-113.

7. Maffei R, et al. The monocytic population in chronic lymphocytic leukemia shows altered composition and deregulation of genes involved in phagocytosis and inflammation. Haematologica. 2013;98(7):1115-1123.

8. Giannopoulos K, et al. Characterization of regulatory T cells in patients with B-cell chronic lymphocytic leukemia. Oncol Rep. 2008;20(3):677-682.

9. Riches JC, et al. T cells from CLL patients exhibit features of T-cell exhaustion but retain capacity for cytokine production. Blood. 2013;121(9):1612-1621.

10. Jitschin R, et al. CLL-cells induce IDOhi
CD14 ${ }^{+}$HLA-DRlo myeloid-derived suppressor cells that inhibit T-cell responses and promote TRegs. Blood. 2014;124(5):750-760.

11. Stiff A, et al. Myeloid-derived suppressor cells express bruton's tyrosine kinase and can be depleted in tumor-bearing hosts by ibrutinib treatment. Cancer Res. 2016;76(8):2125-2136.

12. Kondo K, et al. Ibrutinib modulates the immunosuppressive CLL microenvironment through STAT3-mediated suppression of regulatory B-cell function and inhibition of the PD-1/PD-L1 pathway. Leukemia. 2018;32(4):960-970.

13. Long $\mathrm{M}$, et al. Ibrutinib treatment improves $\mathrm{T}$ cell number and function in CLL patients. J Clin Invest. 2017;127(8):3052-3064.

14. Ruella M, et al. The addition of the BTK inhibitor ibrutinib to anti-CD19 chimeric antigen receptor T cells (CART19) improves responses against mantle cell lymphoma. Clin Cancer Res. 2016;22(11):2684-2696.

15. Dubovsky JA, et al. Ibrutinib is an irreversible molecular inhibitor of ITK driving a Th1selective pressure in T lymphocytes. Blood. 2013;122(15):2539-2549.

16. Lampson BL, et al. Idelalisib given front-line for treatment of chronic lymphocytic leukemia causes frequent immune-mediated hepatotoxicity. Blood. 2016;128(2):195-203.

17. Coutre S, et al. Safety of idelalisib in B-cell malignancies: integrated analysis of eight clinical trials. JClin Oncol. 2015;33(15_suppl):e18030.

18. Okkenhaug K, et al. Impaired B and T cell antigen receptor signaling in p110delta PI 3-kinase mutant mice. Science. 2002;297(5583):1031-1034.

19. Guo H, Samarakoon A, Vanhaesebroeck B, Malarkannan S. The p110 delta of PI3K plays a critical role in NK cell terminal maturation and cytokine/chemokine generation. JExp Med. 2008;205(10):2419-2435.

20. Kim N, et al. The p110delta catalytic isoform of PI3K is a key player in NK-cell development and cytokine secretion. Blood.2007;110(9):3202-3208.

21. Uno JK, et al. Altered macrophage function contributes to colitis in mice defective in the phosphoinositide-3 kinase subunit $110 \delta$. Gastroenterology. 2010;139(5):1642-1653.e1.

22. Ji H, et al. Inactivation of PI3Kgamma and PI3Kdelta distorts T-cell development and causes multiple organ inflammation. Blood. 2007;110(8):2940-2947.

23. Herman SE, Johnson AJ. Molecular pathways: targeting phosphoinositide 3-kinase p110-delta in chronic lymphocytic leukemia. Clin Cancer Res. 2012;18(15):4013-4018.

24. Okkenhaug K, Burger JA. PI3K signaling in normal B cells and chronic lymphocytic leukemia (CLL). Curr Top Microbiol Immunol. 2016;393:123-142.

25. Ringshausen I, et al. Constitutively activated phosphatidylinositol-3 kinase (PI-3K) is involved in the defect of apoptosis in B-CLL: association with protein kinase Cdelta. Blood. 2002;100(10):3741-3748.

26. Clayton E, et al. A crucial role for the p110delta subunit of phosphatidylinositol 3-kinase in $\mathrm{B}$ cell development and activation. J Exp Med. 2002;196(6):753-763.

27. Furman RR, et al. Idelalisib and rituximab in relapsed chronic lymphocytic leukemia. NEngl JMed. 2014;370(11):997-1007.

28. Flinn IW, et al. Duvelisib, a novel oral dual inhibitor of PI3K- $\delta, \gamma$, is clinically active in 
advanced hematologic malignancies. Blood. 2018;131(8):877-887.

29. Chantry D, et al. p110 $\delta$, a novel phosphatidylinositol 3-kinase catalytic subunit that associates with $\mathrm{p} 85$ and is expressed predominantly in leukocytes. J Biol Chem. 1997;272(31):19236-19241.

30. Hock BD, MacPherson SA, McKenzie JL. Idelalisib and caffeine reduce suppression of $\mathrm{T}$ cell responses mediated by activated chronic lymphocytic leukemia cells. PLoS One. 2017;12(3):e0172858.

31. Ali K, et al. Inactivation of PI(3)K p110 breaks regulatory T-cell-mediated immune tolerance to cancer. Nature. 2014;510(7505):407-411.

32. Bowers JS, et al. PI3K $\delta$ inhibition enhances the antitumor fitness of adoptively transferred $\mathrm{CD} 8^{+}$ T cells. Front Immunol. 2017;8:1221.

33. Jou ST, et al. Essential, nonredundant role for the phosphoinositide 3-kinase p110delta in signaling by the B-cell receptor complex. Mol Cell Biol. 2002;22(24):8580-8591.

34. Okkenhaug K, Patton DT, Bilancio A, Garçon F, Rowan WC, Vanhaesebroeck B. The p110delta isoform of phosphoinositide 3-kinase controls clonal expansion and differentiation of Th cells. J Immunol. 2006;177(8):5122-5128.

35. Szczepanski MJ, et al. Increased frequency and suppression by regulatory $\mathrm{T}$ cells in patients with acute myelogenous leukemia. Clin Cancer Res. 2009;15(10):3325-3332.

36. Zhou $Q$, et al. Program death-1 signaling and regulatory $\mathrm{T}$ cells collaborate to resist the function of adoptively transferred cytotoxic $\mathrm{T}$ lymphocytes in advanced acute myeloid leukemia. Blood. 2010;116(14):2484-2493.

37. Beyer $\mathrm{M}$, et al. Reduced frequencies and suppressive function of $\mathrm{CD} 4+\mathrm{CD} 25 \mathrm{hi}$ regulatory $\mathrm{T}$ cells in patients with chronic lymphocytic leukemia after therapy with fludarabine. Blood. 2005;106(6):2018-2025.

38. Fabbri G, et al. Analysis of the chronic lymphocytic leukemia coding genome: role of NOTCH1 mutational activation. J Exp Med. 2011;208(7):1389-1401.

39. Goolsby CL, Kuchnio M, Finn WG, Peterson L. Expansions of clonal and oligoclonal $\mathrm{T}$ cells in B-cell chronic lymphocytic leukemia are primarily restricted to the CD3(+)CD8(+) T-cell population. Cytometry. 2000;42(3):188-195.

40. Van den Hove LE, et al. Peripheral blood lymphocyte subset shifts in patients with untreated hematological tumors: evidence for systemic activation of the T cell compartment. Leuk Res. 1998;22(2):175-184.

41. Görgün G, Holderried TA, Zahrieh D, Neuberg D, Gribben JG. Chronic lymphocytic leukemia cells induce changes in gene expression of $\mathrm{CD} 4$ and CD8 T cells. J Clin Invest. 2005;115(7):1797-1805.

42. Ramsay AG, et al. Chronic lymphocytic leukemia $\mathrm{T}$ cells show impaired immunological synapse formation that can be reversed with an immunomodulating drug. J Clin Invest. 2008;118(7):2427-2437.

43. Casamayor-Palleja M, Khan M, MacLennan IC. A subset of $\mathrm{CD} 4+$ memory $\mathrm{T}$ cells contains preformed $\mathrm{CD} 40$ ligand that is rapidly but transiently expressed on their surface after activation through the T cell receptor complex. JExp Med. 1995;181(4):1293-1301.
44. Pascutti MF, et al. IL-21 and CD4OL signals from autologous $T$ cells can induce antigenindependent proliferation of CLL cells. Blood. 2013;122(17):3010-3019.

45. Bichi R, et al. Human chronic lymphocytic leukemia modeled in mouse by targeted TCL1 expression. Proc Natl Acad Sci US A. 2002;99(10):6955-6960.

46. Gorgun G, et al. E(mu)-TCL1 mice represent a model for immunotherapeutic reversal of chronic lymphocytic leukemia-induced T-cell dysfunction. Proc Natl Acad Sci U S A. 2009;106(15):6250-6255.

47. Hofbauer JP, et al. Development of CLL in the TCL1 transgenic mouse model is associated with severe skewing of the T-cell compartment homologous to human CLL. Leukemia. 2011;25(9):1452-1458.

48. Widhopf GF, et al. ROR1 can interact with TCL1 and enhance leukemogenesis in E $\mu$-TCL1 transgenic mice. Proc Natl Acad Sci U S A. 2014;111(2):793-798.

49. Gassner FJ, et al. Chronic lymphocytic leukaemia induces an exhausted $\mathrm{T}$ cell phenotype in the TCL1 transgenic mouse model. Br J Haematol. 2015;170(4):515-522.

50. Johnson AJ, et al. Characterization of the TCL-1 transgenic mouse as a preclinical drug development tool for human chronic lymphocytic leukemia. Blood. 2006;108(4):1334-1338.

51. Ramsay AG, Evans R, Kiaii S, Svensson L, Hogg N, Gribben JG. Chronic lymphocytic leukemia cells induce defective LFA-1-directed T-cell motility by altering Rho GTPase signaling that is reversible with lenalidomide. Blood. 2013;121(14):2704-2714.

52. Pekarsky Y, et al. Tcl1 enhances Akt kinase activity and mediates its nuclear translocation. Proc Natl Acad Sci U S A. 2000;97(7):3028-3033.

53. Chen SS, et al. Epigenetic alterations in a murine model for chronic lymphocytic leukemia. Cell Cycle. 2009;8(22):3663-3667.

54. Gaudio E, et al. Tcl1 interacts with Atm and enhances NF-кB activation in hematologic malignancies. Blood. 2012;119(1):180-187.

55. Reif K, Okkenhaug K, Sasaki T, Penninger JM, Vanhaesebroeck B, Cyster JG. Cutting edge: differential roles for phosphoinositide 3-kinases, p110 $\gamma$ and $\mathrm{p} 110 \delta$, in lymphocyte chemotaxis and homing. J Immunol. 2004;173(4):2236-2240.

56. Yuan R, et al. Aging in inbred strains of mice: study design and interim report on median lifespans and circulating IGF1 levels. Aging Cell. 2009;8(3):277-287.

57. Woyach JA, et al. Bruton's tyrosine kinase (BTK) function is important to the development and expansion of chronic lymphocytic leukemia (CLL). Blood. 2014;123(8):1207-1213.

58. Göthert JR, et al. Expanded CD8 ${ }^{+} \mathrm{T}$ cells of murine and human CLL are driven into a senescent KLRG1 ${ }^{+}$effector memory phenotype. Cancer Immunol Immunother. 2013;62(11):1697-1709.

59. Curiel TJ. Regulatory T cells and treatment of cancer. Curr Opin Immunol. 2008;20(2):241-246.

60. Patton DT, et al. Cutting edge: the phosphoinositide 3-kinase p110 delta is critical for the function of $\mathrm{CD} 4^{+} \mathrm{CD} 25^{+} \mathrm{Foxp}^{+}$regulatory T cells. J Immunol. 2006;177(10):6598-6602.
61. De Kouchkovsky I, Abdul-Hay M. ‘Acute myeloid leukemia: a comprehensive review and 2016 update'. Blood Cancer J. 2016;6(7):e441.

62. Holler C, et al. PKCbeta is essential for the development of chronic lymphocytic leukemia in the TCL1 transgenic mouse model: validation of PKCbeta as a therapeutic target in chronic lymphocytic leukemia. Blood. 2009;113(12):2791-2794.

63. Lutzny G, et al. Protein kinase c- $\beta$-dependent activation of NF- $\mathrm{KB}$ in stromal cells is indispensable for the survival of chronic lymphocytic leukemia B cells in vivo. Cancer Cell. 2013;23(1):77-92.

64. Nguyen PH, et al. LYN kinase in the tumor microenvironment is essential for the progression of chronic lymphocytic leukemia. Cancer Cell. 2016;30(4):610-622.

65. Nganga VK, et al. Accelerated progression of chronic lymphocytic leukemia in E $\mu$-TCL1 mice expressing catalytically inactive RAG1. Blood. 2013;121(19):3855-3366.

66. Herman SE, et al. Phosphatidylinositol 3-kinase- $\delta$ inhibitor CAL-101 shows promising preclinical activity in chronic lymphocytic leukemia by antagonizing intrinsic and extrinsic cellular survival signals. Blood. 2010;116(12):2078-2088.

67. Hoellenriegel J, et al. The phosphoinositide 3'-kinase delta inhibitor, CAL-101, inhibits B-cell receptor signaling and chemokine networks in chronic lymphocytic leukemia. Blood. 2011;118(13):3603-3612.

68. Balakrishnan K, et al. The phosphoinositide-3kinase (PI3K)-delta and gamma inhibitor, IPI-145 (Duvelisib), overcomes signals from the PI3K/ AKT/S6 pathway and promotes apoptosis in CLL. Leukemia. 2015;29(9):1811-1822.

69. Fiorcari S, et al. The PI3-kinase delta inhibitor idelalisib (GS-1101) targets integrin-mediated adhesion of chronic lymphocytic leukemia (CLL) cell to endothelial and marrow stromal cells. PLoS One. 2013;8(12):e83830.

70. McClanahan F, et al. Mechanisms of PD-L1/ PD-1-mediated CD8 T-cell dysfunction in the context of aging-related immune defects in the E $\mu$-TCL1 CLL mouse model. Blood. 2015;126(2):212-221.

71. Sallusto F, Geginat J, Lanzavecchia A. Central memory and effector memory $\mathrm{T}$ cell subsets: function, generation, and maintenance. Annu Rev Immunol. 2004;22:745-763.

72. Kocher T, et al. $\mathrm{CD} 4^{+} \mathrm{T}$ cells, but not non-classical monocytes, are dispensable for the development of chronic lymphocytic leukemia in the TCL1-tg murine model. Leukemia. 2016;30(6):1409-1413.

73. Yu P, et al. Intratumor depletion of $\mathrm{CD} 4^{+}$cells unmasks tumor immunogenicity leading to the rejection of late-stage tumors. JExp Med. 2005;201(5):779-791.

74. Mohme M, Riethdorf S, Pantel K. Circulating and disseminated tumour cells - mechanisms of immune surveillance and escape. Nat Rev Clin Oncol. 2017;14(3):155-167.

75. Liu D, Uzonna JE. The p110 delta isoform of phosphatidylinositol 3-kinase controls the quality of secondary anti-Leishmania immunity by regulating expansion and effector function of memory $\mathrm{T}$ cell subsets. JImmunol. 2010;184(6):3098-3105.

76. Honda K, Littman DR. The microbiota in adap- 
tive immune homeostasis and disease. Nature. 2016;535(7610):75-84.

77. Johansson ME, et al. Normalization of host intestinal mucus layers requires long-term microbial colonization. Cell Host Microbe. 2015;18(5):582-592.

78. Spiljar M, Merkler D, Trajkovski M. The immune system bridges the gut microbiota with systemic energy homeostasis: focus on TLRs, mucosal barrier, and SCFAs. Front Immunol. 2017;8:1353.
79. Levy M, Kolodziejczyk AA, Thaiss CA, Elinav E. Dysbiosis and the immune system. Nat Rev Immunol. 2017;17(4):219-232.

80. Gopalakrishnan V, Helmink BA, Spencer CN, Reuben A, Wargo JA. The influence of the gut microbiome on cancer, immunity, and cancer immunotherapy. Cancer Cell. 2018;33(4):570-580.

81. Steinbach EC, et al. Innate PI $3 \mathrm{~K}$ p $110 \delta$ regulates Th1/Th17 development and microbiota-dependent colitis. JImmunol. 2014;192(8):3958-3968.
82. Vanhaesebroeck B, et al. P1108, a novel phosphoinositide 3-kinase in leukocytes. Proc Natl Acad Sci U S A. 1997;94(9):4330-4335.

83. Sujobert $P$, et al. Essential role for the p110delta isoform in phosphoinositide 3-kinase activation and cell proliferation in acute myeloid leukemia. Blood. 2005;106(3):1063-1066.

84. Lapalombella R, et al. Tetraspanin CD37 directly mediates transduction of survival and apoptotic signals. Cancer Cell. 2012;21(5):694-708. 